\title{
Putting susceptibility on the map to improve conservation planning, an example with terrestrial mammals
}

Article

Accepted Version

Polaina, E., Revilla, E. and Gonzalez-Suarez, M. (2016) Putting susceptibility on the map to improve conservation planning, an example with terrestrial mammals. Diversity and Distributions. ISSN 1472-4642 doi: https://doi.org/10.1111/ddi.12452 Available at https://centaur.reading.ac.uk/65808/

It is advisable to refer to the publisher's version if you intend to cite from the work. See Guidance on citing.

To link to this article DOI: http://dx.doi.org/10.1111/ddi.12452

Publisher: Wiley

All outputs in CentAUR are protected by Intellectual Property Rights law, including copyright law. Copyright and IPR is retained by the creators or other copyright holders. Terms and conditions for use of this material are defined in the End User Agreement.

www.reading.ac.uk/centaur 
Central Archive at the University of Reading

Reading's research outputs online 
Putting susceptibility on the map to improve conservation planning, an example with terrestrial mammals

Polaina, Ester ${ }^{\mathrm{a}}$ (e.polaina@ebd.csic.es)

Revilla, Eloy (revilla@ebd.csic.es)

González-Suárez, Manuela, (manuela.gonzalez@ebd.csic.es)

a Department of Conservation Biology, Estación Biológica de Doñana-CSIC, Calle Américo Vespucio s/n, 41092 Sevilla, Spain.

${ }^{\mathrm{b}}$ School of Biological Sciences, University of Reading, Whiteknights, Reading, RG6 6AS, UK

Key words: anthromes, extinction risk, IUCN Red List, life-history traits, terrestrial mammals, zonation

Running title: From species vulnerability to spatial susceptibility

Corresponding author: Ester Polaina, e.polaina@ebd.csic.es

Abstract word count: 301

Main text word count: 5362

Number of references: 62

Article type: Biodiversity Research and Reviews 


\begin{abstract}
Aim

To propose a general approach to spatially synthesize known predictors of vulnerability at the species level in order to identify areas directly associated with specific conservation problems. Under this problem-detection framework, the coincidence or divergence of main strengths and weaknesses can be used to propose tailor-made conservation strategies. This approach is illustrated for terrestrial mammal species evaluating two of their main components of vulnerability: life-history traits and land use pressure.
\end{abstract}

\title{
Location
}

Global.

\section{Methods}

We determine, at the species level, the relationships between extinction risk and two well-known predictors of vulnerability: life-history traits (intrinsic) and land use (extrinsic). Transferring these findings into the spatial domain, we identify the areas of the world where one of these two facets is predominant and those areas where both coincide.

\section{Results}

The proposed approach allows us to recognize four types of areas: 1) double-susceptibility areas: where both the characteristics of the species and the existing human activities pose a threat, therefore the simultaneous management of both species/habitats and human activities are needed; 2) intrinsicsusceptibility areas: where species are naturally fragile and human presence is scarce, thus speciesspecific management plans would be particularly efficient; 3) extrinsic-susceptibility areas: where human pressure is high but species are not intrinsically vulnerable; which requires special attention 
to human activities; and 4) low-susceptibility areas: where there are not remarkable threats for existing terrestrial mammals, which additionally are not particularly fragile.

\section{Main conclusions}

Our approach can spatially synthesize known predictors of vulnerability identifying areas where different factors predispose species to become extinct. This method builds on conservation planning approaches by targeting actions based on known strengths and weaknesses of a given area, and offering a new implementation of comparative studies of extinction risk. This approach may be applied to different species and to particular regions, focusing on different drivers, and complemented by incorporating social and economic trade-offs. 


\section{Introduction}

Since Myers $(1989,1990)$ first identified the now-famous global hotspots of biodiversity, many different criteria have been applied to identify areas of the planet that most "deserve" limited conservation resources (e.g. Olson \& Dinerstein 2002) and numerous methods are available to define optimal networks of protected areas (Moilanen et al., 2009). While the practical applications of global prioritization studies have been debated (Tulloch et al., 2015), it is accepted that these efforts are important to raise awareness about where the critical areas and species to preserve are. Indeed, these studies can have great success in mobilizing resources; e.g., by 2003 over US\$750 million in funding had been invested in the global hotspots identified by Myers (Brooks et al., 2006).

Systematic conservation planning (SCP) focuses on the spatial facet of conservation actions by identifying important areas for biodiversity that may be considered for protection (Watson et al., 2011), aiming to optimize the benefits per investment of proposed conservation measures and to achieve economically feasible targets (Naidoo et al., 2006; Underwood et al., 2008). SCP largely relies on the concepts of irreplaceability (likelihood that a site is strictly necessary to meet some targets, e.g., preserve the maximum functional diversity) and vulnerability (risk of a site being transformed, e.g., by human use of land), considering that high values of both are desirable to prioritize an area (Margules \& Pressey, 2000); however, additional properties can be defined to select areas to preserve (see Kukkala \& Moilanen 2013 for a review). Furthermore, some studies have incorporated species' intrinsic traits to identify areas to prioritize, e.g., sites where more species are likely to become threatened (Cardillo et al., 2006), or where species recovery would be more probable (Di Marco et al., 2012), demonstrating the value of including knowledge at the species' level into conservation planning.

Nevertheless, conservation-prioritization schemes are supposed to prescribe more than areas to protect (Game et al., 2013). There is a broad spectrum of proposals to complement this approach, such as land use zoning, which proposes a range of management actions for the whole territory 
(Watts et al., 2009); prioritizing management of specific threats according to local sensibilities (Carwardine et al., 2012; Auerbach et al., 2015); dynamic reserves' delimitation, accounting for dynamic features of the landscape (Leroux et al., 2007); or specific plans for most endangered species (Vargas et al., 2008), among others. In fact, most of the world land is not a protected area (IUCN \& UNEP-WCMC, 2015), but other conservation actions can, to a greater or lesser extent, be implemented independently of the protection level of an area; thus there is a need to create guidelines to identify what can and should be done in different regions. Complementing SCP with a global framework to prioritize conservation actions should provide the next step in the identification of valuable areas for conservation while offering practical information relevant for conservation management.

At the species level, the comparative literature on extinction risk has dedicated considerable effort to identify key factors that make some species more vulnerable to extinction. Some of these studies have concentrated on intrinsic species traits (Davidson et al., 2009; González-Suárez \& Revilla, 2013), others have focused on external drivers related to the degree of anthropization within species geographic range (Pekin \& Pijanowski, 2012), and some have combined both aspects to compare the importance of intrinsic vs. extrinsic predictors of vulnerability (Cardillo et al., 2005), or to explore their interactions (González-Suárez et al., 2013). Vulnerability reflects a combination of the intrinsic characteristics of the species and the extrinsic human threats to which it is exposed. Incorporating this knowledge into to the spatial facet may help to prioritize actions according to the particular weaknesses and strengths of different areas.

One step forward in the delimitation of areas for conservation is to consider the processes leading to vulnerability in order to develop more targeted conservation actions. In this study we incorporate information on the main predictors of vulnerability at the species level — both intrinsic and extrinsic — and then map areas where they differentially occur, aiming to prioritize conservation actions according to the main weaknesses and strengths of each area. To illustrate our approach, we 
use global data on terrestrial mammals because this is a charismatic, well-studied group for which data are available at the global scale.

Particularly, we identify intrinsically vulnerable hotspots using data on species' traits that have consistently been associated with vulnerability to extinction at the species level. Additionally, we define extrinsically vulnerable areas as those with higher levels of anthropization, reflecting primarily human land use as a key global threat for mammals. Overall vulnerability is then evaluated combining both types of factors to obtain a global zonation that differentiates susceptibilities and thus, allows distinguishing areas in which different conservation management strategies (e.g., manage the species, manage human activities, or both) may be advisable. The present study does not aim to be a comprehensive review of all known vulnerability factors for particular species or to propose a final global prioritization map for mammals. Instead, we propose and illustrate the potential of an easy-to-implement approach to detect areas of susceptibility and frame conservation actions. Although we use terrestrial mammals as an example here, focusing on few key predictors at a global scale, this approach could be extended to other taxa, other spatial scales, and to include different or additional predictors of vulnerability, with the only constraint of data availability.

\section{Methods}

To define spatially-explicit intrinsic and extrinsic vulnerability maps we followed two steps briefly summarized here and described in more detail in the next sections. First, we fitted regression models at the species level (species-based models) to define relationships between predictors of intrinsic or extrinsic vulnerability (PV) and global threat status (Fig.1, A-B). Species' threat status was defined using the IUCN Red List (IUCN, 2014) with categories converted into an ordered numeric scale (LC, 0; NT, 1; VU, 2; EN, 3; CR, 4). Second, we used the obtained regression's coefficients to spatially predict vulnerability (spatial predictions) according to the characteristics of the terrestrial mammals occurring within each $1^{\circ} \times 1^{\circ}$ cell of a grid covering the world's land surface (intrinsic vulnerability), 
and according to the human land use within each cell (extrinsic vulnerability. Fig. 1, C-D). Finally, we spatially quantified the degree of agreement/disagreement of both vulnerability predictions by means of bivariate local spatial autocorrelation (Fig. 1E; see below). All spatial data were convened using the equal-area projection Eckert IV, WGS84, in ArcView 3.2 and ArcGIS 9.3 (ESRI, 1999, 2008).

\section{Species-based models: Intrinsic predictors of vulnerability}

The selection of traits included in the analyses was based on results from previous studies of extinction risk in terrestrial mammal species at the global scale. A recent publication (Verde Arregoitia, 2016) exhaustively reviews this issue. Excluding studies focusing on particular mammalian groups or regions (which have a different scope than the present study) we identified 11 global studies — from the 68 in the review_ covering terrestrial mammals in general (see Table S1 in Supplementary Information). Those 11 studies consistently tested and identified as relevant four traits: adult body mass, geographical range, population density and weaning age (Figure S1). These four traits were also consistently identified as most relevant in the general review, considering regional- and taxa- specific studies, completed by Verde Arregoitia (2016).

For our analyses we retrieved species-level data for adult body mass, population density and weaning age from the freely available PanTHERIA database (Jones et al. 2009; Table S2). Estimates of the geographic range area for each species were calculated using the IUCN distribution data (IUCN 2014) for terrestrial mammals, selecting only areas identified as native in origin and presence classified as extant or probably extant. We acknowledge that current geographic range is not a purely intrinsic characteristic of a species, since it is widely influenced by external factors, such as climate or human activities (Laliberte \& Ripple, 2004; Di Marco \& Santini, 2015). Still, geographic range sizes capture ecological and dispersal attributes that can influence extinction risk and are not well- 
captured by any of the other intrinsic or extrinsic vulnerability indicators included in the present work.

We accounted for lack of independence when working at the species level by adjusting phylogenetic generalized least-squares (PGLS) regressions based on the updated mammalian supertree of Bininda-Emonds et al. (2007) presented by Fritz et al. (2009). PGLS models were fitted using the procedure pgls within the R-package 'caper' (Orme et al., 2013; R Core Team, 2014). Correlation among predictors was tested to avoid collinearity (Table S3). Population density was excluded, due to its high correlation with adult body mass $(\rho=-0.76)$ and its lower sample size. PGLS included the selected intrinsic traits as independent variables $\left(\log _{10}\right.$-transformed) and the numeric IUCN threat status as the dependent variable. This simplification considers IUCN categories as a continuous and thus, assumes differences among categories are equal, which may not be realistic. Nevertheless, using a numeric threat status allows us to account for phylogenetic signal in explanatory variables, to rank predictions from lower to higher risk, and to easily compare our findings with previous literature using equivalent approaches (e.g. Purvis et al., 2000; Di Marco et al., 2012). Species with status defined as Data Deficient (DD), Extinct (EX) or Extinct in the Wild (EW) were not considered for the analysis $\left(\mathrm{N}_{\mathrm{DD}}=788 ; \mathrm{N}_{\mathrm{EX}}=73 ; \mathrm{N}_{\mathrm{EW}}=2\right)$. To avoid circularity we excluded species listed as threatened by the IUCN under criteria B (based on the size of their geographic range, $\mathrm{N}=554)$. In addition, some species could not be included because phylogenetic relationships were not defined $(\mathrm{N}=13)$ or trait data were not available for all three traits $(\mathrm{N}=2953)$. The final model was fitted for 981 terrestrial mammal species.

Acknowledging the reduced and biased sample size representing intrinsic vulnerability of terrestrial mammals, we fitted alternative models to assess sensibility of results to data availability. To increment the sample size, we (1) included all terrestrial mammals not excluding species listed under criterion B but eliminating geographic range as a predictor (sample size increased to $\mathrm{N}=1027$ ); and (2) built a model including the two most data-complete and least correlated traits: body mass and 
geographic range (Table S3; sample size increased to $\mathrm{N}=2747$ ). (3) We considered the option of imputing missing data as done in recent studies based on large incomplete trait databases (Di Marco \& Santini, 2015), acknowledging that they are likely missing not at random (Nakagawa \& Freckleton, 2008). To do that, we employed the phylopars and phylopars.predicts functions from the 'Rphylopars' package in R (Goolsby et al., 2015); this approach incorporates phylogenetic information and relationships among variables to impute data and has been shown to perform well imputing data for similar traits (Penone et al., 2014). However, for weaning age we lack data for $>70 \%$ of species, thus, results based on imputed data need to be interpreted with caution. Lastly, to explore the biases in data availability between small and large species (because the latter are better studied; González-Suárez et al. 2012) we performed separate analyses for small (body mass $\leq 3 \mathrm{~kg}$; Cardillo et al. 2005) and large mammals (body mass > 3kg).

\section{Species-based models: Anthropogenic predictors of vulnerability}

We estimated the degree of anthropization within each species geographic range based on the anthromes global classification by Ellis \& Ramankutty (2008). In particular, we used the series corresponding to the year 2000 from “Anthropogenic Biomes v.2” (Ellis et al., 2010). This classification provides an integrated perspective with a gradient ranging from low to highly modified areas, and recognizes six broad groups (anthromes): wildlands (woodlands and barren lands), seminatural lands (inhabited woodlands and barren lands), rangelands, croplands, villages and dense settlements (Table S4).

As in the previous section, we fitted PGLS to test the relationship between anthromes' composition at the species level and IUCN threat status as a numerical response. The predictors were the proportions of each species' range covered by each of the anthromes mentioned above. Due to topological errors (discrepancies between IUCN geographic ranges and anthromes spatial database), for some species the sum of all anthromes proportions represented $<95 \%$ of their geographic range; 
these species were not included in the analyses ( $N=86$, Table S5). Species not included in the phylogeny were also excluded $(\mathrm{N}=440)$. Compositional data present challenges for analyses because of the implicit relationship between proportions: the increase of one necessarily implies a decrease in another (or several at the same time), which is not reflected by a simple correlation test (Table S6). As in Aitchison \& Egozcue (2005) we used a log-ratio transformation: one category is defined as a reference (in our case dense settlements, the most modified anthrome) and the other values are calculated as ratios from that reference. We used the Aitchison zero replacement procedure (Aitchison, 2003) as described in Fry et al. (2000), which replaces values as follows:

$$
C_{i}=\left\{\begin{array}{cc}
\delta(M+1)(N-M) / N^{2} & \text { component }=0 \\
i-\left(\delta M(M+1) / N^{2}\right) & \text { otherwise }
\end{array}\right.
$$

Eq 1.

Where, $C_{i}$ is the new component value (in parts per unit), $\delta$ is the maximum rounding error (we used the minimum overlapping percentage estimated: $8.02 \cdot 10^{-7}$ ), $N$ is the total number of components (in our case always 6), $M$ the number of components that are zero (which varies among observations), and $i$ is the original component with a non-zero value.

Because distribution data were available for many more species than life-history trait data, the number of species available for this analysis was notably higher than in the traits-based models. To ensure that differences in sample size were not driving our results, we defined anthropogenic models for both the whole set of species with distributional data meeting the requirements above ( $N=3908)$, and the same subset of species for which the main intrinsic-traits model was fitted. To partly account for the fact that different species may be exposed to different threats (GonzálezSuárez et al., 2013), and to allow for the assessment of spatial coincidence/divergence in relation to intrinsic vulnerability, we also built separate models for small (body mass $\leq 3 \mathrm{~kg}$. $\delta=8.02 \cdot 10^{-7}$ in eq. 1) and large terrestrial mammals (body mass $>3 \mathrm{~kg} . \delta=1.99 \cdot 10^{-6}$ in eq. 1 ). Additionally, we built a 
full model including both intrinsic and extrinsic predictors to weight the relative contribution of each of them in explaining threat status (Table S7).

\section{Spatial predictions}

To make spatial predictions from the species-based models we first defined a $1 \times 1^{\circ}$ grid covering the world emerged surface. We overlapped this grid with the IUCN geographic distribution range data for each mammalian species to determine which species occur in each cell. To predict intrinsic vulnerability per grid cell, we defined cell values of body mass, geographic range and weaning age as the median value obtained from all species occurring in a given cell and for which trait data were available. These median trait values aim to depict the representative mammal occurring within each grid cell. Medians were preferred over mean values to counteract the overrepresentation of large mammals in the life-history traits database. For predicting extrinsic vulnerability we superimposed the $1 \times 1^{\circ}$ global grid and the anthromes layers to calculate the proportion of each cell occupied by each of the anthrome categories. Proportion values (compositional data) were transformed using equation $1\left(\delta=1.28 \cdot 10^{-06}\right)$. Alternatively, we predicted intrinsic and extrinsic vulnerability (separately) as the mean species-based vulnerability for all present species in each grid cell (Cardillo et al., 2006).

Finally, to evaluate the spatial coincidence of both types of vulnerability, we computed bivariate local Moran's I values (local indicators of spatial association, LISA) and cluster maps with the software GeoDa (Anselin et al., 2006), considering first order queen spatial weights (cells sharing at least one point are neighbours), and a significance level of $p<0.01$ for cluster inclusion. This analysis classifies clusters based on the values of each grid cell and its neighbouring grid cells; four combinations are possible high-high, low-low (both positive spatial autocorrelation values), high-low and low-high (both negative spatial autocorrelation values). High or low values are defined in relation to the mean value of the given set of data; i.e. high values of intrinsic vulnerability are those 
over the mean predicted intrinsic vulnerability for all grid cells, and low values are those under the mean; and the same for extrinsic vulnerability.

\section{Results}

Species-based models: Intrinsic predictors of vulnerability

As expected, our regression analyses suggest that larger mammals, occupying small geographic ranges and with older weaning age tend to be at higher risk (Table 1). These relationships are generally supported by alternative versions of the model (Table S8), except for the alternative model including imputed data which suggests that earlier weaning ages increase risk, a biologically counterintuitive result (Model I4, Table S8). This relationship appears to be an artefact of the imputation technique itself, as imputed data values vary widely depending on the different subset of variables that are considered for the imputation (Fig. S2). Results based on data imputation for traits with significant data gaps needs to be interpreted with great caution and here we feel relying on nonimputed data is more sensible. The model including three traits (without imputation) presents the highest adjusted $\mathrm{R}^{2}$, similarly to the alternative model excluding weaning age, with practically identical coefficient estimates (Model I3, Table S8). Broadly, results are qualitatively the same when large and small mammals are analyzed separately, except that weaning age is not a significant predictor of threat status for large mammals (Table 1).

\section{Species-based models: Anthropogenic predictors of vulnerability}

Our analyses suggest that greater overlap with croplands and semi-natural lands is associated with higher threat status in terrestrial mammals; whereas greater overlap with wildlands is associated with lower risk (for all mammals, and for large and small species separately). Overlap with villages has no significant effect in any of the tested models (Tables 2 and S9). Greater overlap with rangelands has 
no significant effect when all mammals are analyzed together likely because there are opposite effects between groups: more overlap is associated with higher risk in small mammals but with lower risk in large mammals (Table 2). Results are qualitatively the same for a model fitted only for species with available intrinsic traits' data, with a notable decrease in the adjusted $\mathrm{R}^{2}$ (Table S9).

Overall, species-based models based on intrinsic traits have more explanatory power than those based on anthropogenic effects, with more pronounced differences when comparing models fitted for the same subset of species (Model I1 vs. A2, Tables S8 and S9). However, anthropogenic variables clearly play a role in explaining species' threat status (Tables 1 and 2) as supported when both intrinsic and extrinsic indicators are analyzed together (Table S10).

\section{Spatial predictions}

Here we focus on predictions based on median trait values per grid cell (intrinsic vulnerability) and extrinsic vulnerability predicted from the proportion of grid-cell covered by different anthromes (extrinsic vulnerability). These predictions are the most robust to data biases and limitations (i.e., which subset of mammals is employed to fit the species-based models; Appendix S3). Broad scale differences between this approach and the alternative approach of averaging the predicted vulnerability for all species occurring within a grid-cell are generally small, being more evident for extrinsic vulnerability, where predictions are correlated only at 0.60 (Spearman's $\rho$; Table S12, Fig. S4). Comparing intrinsic vulnerability predictions, they present Spearman's $\rho$ correlation values between 0.77 (full model) and 0.91 (including only geographic range and body mass, and imputing data; Table S11, Fig. S3). Further discussion of these different outputs is included in Appendix S3. Vulnerability due to intrinsic predictors is estimated for a total of 17980 grid cells, which represent approximately $134.2 \mathrm{M} \mathrm{km}^{2}$ of emerged land $(99.4 \%$ of the total World's land area, excluding Antarctica). Considering all mammals and based on median trait values per grid cell, we find that high intrinsic vulnerability areas occur in diverse parts of the world, including Southeast 
Asia, India, southern and Horn of Africa and the Andes. Areas of low intrinsic vulnerability include most of South America, and Europe (Fig. 2A).

Separate predictions for large and small mammals reveal interesting differences. For example, vulnerability in northern Africa is mostly associated to smaller species (Fig. 2c). In addition, new areas of high intrinsic vulnerability are revealed when examining only small mammals, including Central and South America, and southern Europe (Fig. 2c). Additional patches are revealed in northern Europe and Russia when considering only large mammals (Fig. 2e). Overall, vulnerability patterns are not preeminently driven by any of the two subgroups, with low values of correlation between all-large (Spearman's $\rho=0.19)$, and all-small $(\rho=0.20)$ predictions.

Vulnerability due to extrinsic predictors is estimated for 17631 grid cells, covering around $133.7 \mathrm{M} \mathrm{km}^{2}$ (98.9\% of the World's emerged land, excluding Antarctica). The included surface is slightly smaller than in the intrinsic analysis because Greenland is not included in the anthromes classification. High extrinsic vulnerability areas occur in numerous areas of the World, reflecting widespread human impacts, and include eastern United States, Central America, the coast of Brazil, most of Sub-Saharan Africa, Europe and South East Asia, China, Pakistan, and India (Fig.2b). Predictions based on the separate models for small and large mammals show similar, highly correlated patterns (all vs. small $\rho=0.81$, all vs. large mammals $\rho=0.84$. Figs. $1 \mathrm{~d}$ and $1 \mathrm{f}$ ).

Estimates of spatial association of both vulnerabilities — based on bivariate local Moran's I values - was possible for 17474 grid cells based on the ensemble of terrestrial mammals with available information. We identify four types of clusters: double-susceptibility areas $\left(\sim 20.1 \mathrm{M} \mathrm{km}^{2}\right)$, where high values of intrinsic vulnerability are surrounded by high values, or vice versa (significant positive spatial autocorrelation; $\mathrm{p}<0.01)$; intrinsic-susceptibility areas $\left(\sim 12.3 \mathrm{M} \mathrm{km}^{2}\right)$, where high intrinsic vulnerability values are surrounded by low extrinsic values, or low extrinsic values are surrounded by high values of intrinsic vulnerability (significant negative spatial autocorrelation); extrinsic-susceptibility areas $\left(\sim 25.5 \mathrm{M} \mathrm{km}^{2}\right)$, where high values of extrinsic vulnerability are 
surrounded by low intrinsic vulnerability, or low intrinsic vulnerability values are surrounded by high values of extrinsic vulnerability (significant negative spatial autocorrelation); and lowsusceptibility areas $\left(\sim 16.7 \mathrm{M} \mathrm{km}^{2}\right)$ where low values of intrinsic vulnerability are surrounded by low extrinsic vulnerability values, or vice versa (significant positive spatial autocorrelation). Doublesusceptibility areas occur primarily in Southeast Asia, Madagascar and Sub-Saharan Africa. Intrinsic-susceptibility areas are primarily located in the Sahara region, Botswana-South Africa, Tibet and near the Arctic in the American continent. Extrinsic-susceptibility areas occur in most of Europe, North America, Brazil and parts of southern Africa. Low-susceptibility areas are essentially found in Siberia and small regions of Europe, North and South America (Fig. 3a). The four types of areas together represent $56 \%$ of the global surface for which data are available. The remaining areas present intermediate values of intrinsic and extrinsic vulnerability which are not assigned to particular clusters. (Additional information about zones is included in Appendix S3).

Separate cluster analyses for small (16948 grid cells) and large terrestrial mammals (17183 grid cells) present largely different pictures (Fig. 3). Venn diagrams show how the four zoning categories coincide among the three groups of species (all, small and large; Fig. 3b); overall we find relatively low spatial overlap in assigned cluster type. A 38\% of grid-cells classified as doublesusceptibility areas including all species are equally allocated for separate groups of species, $17 \%$ in the case of extrinsic-susceptibility areas, and $18 \%$ of low-susceptibility areas, whereas only $7 \%$ of intrinsic-susceptibility areas are equally assigned for all groups. Low-susceptibility or doublesusceptibility areas are more widespread when only small species are analyzed; and extrinsicsusceptibility areas occupy the vastest surface when considering large mammals separately (Fig. 3).

\section{Discussion}

Understanding the processes driving vulnerability patterns (or irreplaceability, or any other property worth preserving) should be as important as ranking areas as priority for conservation. With this 
understanding we can move from a prioritization framework to a problem-detection approach that could lead to more effective conservation planning and more informed management decisions. Information about the factors that drive vulnerability is increasingly available at the species level (Kleyer et al., 2008; Frimpong \& Angermeier, 2009; Jones et al., 2009), therefore, the easy-to-follow protocol we present here could be applied to different taxa and at different spatial scales. This approach requires five steps (Fig. 1). The first step is to identify relevant predictors of vulnerability (PV) for the selected group of species (Fig. 1A; e.g. life-history determinants and land use). The second step requires selecting a measure of conservation status (e.g. IUCN status) and establishing the relationship between status and PV (Fig. 1B). The third step is to define the region of interest (e.g. the world emerged surface) and calculate the selected PV values for discrete spatial units (e.g. $1 \times 1^{\circ}$ grid cells; Fig 1C). In step 4 we spatially predict conservation status at the new selected unit (i.e. grid-cell spatial vulnerability; Fig. 1D) based on the identified relationship between PV and conservation status at the species level. The final step consists on evaluating the coincidence or divergence of extreme values of these predictions by any measurement of spatial association (e.g. bivariate local Moran's I) to obtain a spatial summary of the main factors considered and, consequently, to reveal and help prioritize conservation actions within different areas.

The identification of PV does not need to be exhaustive. As illustrated in the present work, the final goal may not be to include all known factors influencing species conservation, but to summarize the ones of interest (e.g., because they are the most worrying in a given area or time) and spatially compare them. Although the two groups of variables considered in the present work are not completely independent (e.g. geographic range is determined by intrinsic properties of a species, like dispersal ability, as well as extrinsic human factors; Di Marco \& Santini, 2015), they represent the two main components of vulnerability discussed in the literature of comparative extinction risk analyses. Certainly, our analysis is a simplification, as other life-history traits (e.g. litter size, diet specialization) and external threats (e.g. invasive species, fire) are relevant for some groups and 
regions, but generality requires focusing on broad, key factors affecting most species. Moreover, to complement the spatial summary, explicit descriptors of socioeconomic development could be considered in order to better define the human context in which decisions are going to take place (Polaina et al., 2015).

The final proposed zonation categories offer a useful summary, which does not reflect hierarchical priorities but categorical descriptors, i.e. double-susceptibility are not more important than the rest, although they may require more resources given their conflictive situation. In fact, the four zone-categories are not a definitive guide for management; additional (or fewer) zones may be defined depending on the conservation goals and available data and resolution. Nevertheless, these categories are useful to identify different types of regions for which diverse management actions may be most useful.

Double-susceptibility areas are, by definition, zones that harbour naturally sensitive fauna, which may be charismatic species able to capture public and institutional attention (Roberge \& Angelstam, 2004), but also may represent difficult — and expensive- conservation targets (Andelman \& Fagan, 2000). Human activities in these areas may also play an important role to threaten species. In our global analyses we found that an important portion of these areas is currently classified as seminatural (Fig. S5) and thus, with potential for human land uses to intensify (Neumann et al., 2010). Proposing conservation actions in these areas requires making difficult trade-offs, since human needs are certainly going to confront with the conservation of sensitive species (Dobrovolski et al., 2011).

Intrinsic-susceptibility areas present similar characteristics to double-susceptibility areas in terms of sensitive fauna; with the subsequent mentioned advantages and difficulties. Human land use in these areas is less threatening in general (mainly deserts and remote areas; Fig S5); thus, humanwildlife conflicts are less likely, which a priori would facilitate any conservation action. 
Nevertheless, human impact may still exist as threats such as hunting and persecution may be a high risk factor for sensitive fauna, including larger species (González-Suárez \& Revilla, 2014).

Extrinsic-susceptibility areas are occupied by species with low intrinsic vulnerability, potentially able to cope with the existing high levels of anthropization (e.g. Wilson et al. 2014); therefore, these areas should be easier to manage. Still, any effective conservation strategy within these areas should include close monitoring of species and an important control of human expansion in the form of land-use intensification, because additional anthropogenic activities could compromise the conservation of even widespread and resilient species. Importantly, many of these regions may actually no longer be intrinsically vulnerable because sensitive species went extinct time ago (Morrison et al., 2007). If correctly managed or restored, these areas could potentially host some of these species again.

Low-susceptibility areas have low-intrinsically vulnerable species and low human impacts. These areas are relatively safe because key factors associated with species vulnerability are largely absent or have limited impact. They present an opportunity to implement potentially inexpensive, low-conflict passive conservation actions that may contribute to maintain the low-susceptibility status in the long term (Sanderson et al., 2002). Nevertheless, additional threats, not included in the analyses, may exist in these areas, so specific recommendations would require a careful evaluation of threats and impacts.

Data quality is a recurrent issue in global analyses including many species; however, our results prove that delimitating broad patterns, differences are generally not qualitative, and that high vulnerability areas can be consistently detected (Appendix S3). Nevertheless, there are likely data biases regarding human land use descriptors, including the fast changes that are occurring in some areas (Verburg et al., 2011) or differences in data quality across regions, which we could not explore and that could influence zonation schemes. At the species level, our analyses for terrestrial mammals reveal intrinsic traits as better predictors of the IUCN threat status than the extrinsic factors 
considered here (namely land use), in agreement with previous studies (e.g. Cardillo et al. 2004). However, this does not imply that external factors are irrelevant, but instead, that this type of statistical methods may adjust better to life-history traits. Species-based models' explanatory power may seem overall low (Adj. $\mathrm{R}^{2}<0.3$ ), however, these low values are in fact higher than the average variance explained by other ecological/evolutionary works (Jennions \& Moller, 2002).

In this study we also explored different approaches to map the main findings at the species level (namely using a median descriptor of traits, or averaging species predictions), which are congruent at the broad scale, but reveal important regional differences for both intrinsic (e.g. Northern South America is often predicted as a low vulnerability area, but in some cases it is detected as vulnerable; Fig. S3) and extrinsic vulnerability (e.g. North America is a low extrinsic vulnerability area when considering mean predictions, but patches of high vulnerability emerge when using real cover values per grid cell; Fig. S4). These regional discrepancies should not be overlooked if using this approach to define conservation actions and strategies. In our example we also found different zonations when small and large terrestrial mammals were analyzed separately. While this separation had an illustrative purpose (to show the effects of data biases) it is important to notice how patterns vary depending on the particular subset of species. For example, in the case of small species, the vast coverage of double-susceptibility areas (Fig. 3) suggests that more human-wildlife conflicts may occur for this subgroup of species than detected by the all-species prediction.

A bewildering mix of advice for global conservation planning has been produced in recent years aiming to delimit the minimum area necessary to protect the endangered species/ecosystems of the world; however, we are still witnessing a decrease in global biodiversity (Ceballos et al., 2015). Here, we present an approach to detect spatial differences in risk which also allows extracting the most of valuable information at the level of species, populations and, potentially, other ecological entities. Focusing on patterns and ignoring the, often complex, processes that drive those patterns can lead to simplistic and inefficient biodiversity conservation strategies (Peres \& Terborgh, 1995). 


\section{Acknowledgments}

We thank the IUCN Red List team for making and maintaining its database freely available online.

We also acknowledge the Laboratory for Anthropogenic Landscape Ecology, directed by Dr. Erle C.

Ellis, for publicly sharing their Anthromes' datasets. We are very grateful to two anonymous

reviewers who provided helpful comments on previous versions of this manuscript. This work was

funded by the program 'Junta para la Ampliación de Estudios' (JAEPre022. BOE-A-2011-10745,

co-funded by the European Social Fund), the European Community's Seventh Framework

Programme (FP7/ grant $n^{\circ} 235897$ and EU BON project $\left.n^{\circ} 308454\right)$, and the Spanish Ministry of

Science and Innovation co-funded by FEDER (CGL2009-07301/BOS, CGL2012-35931/BOS and

JCI-2011-09158).

\section{References}

Aitchison J. \& Egozcue J.J. (2005) Compositional Data Analysis: Where Are We and Where Should We Be Heading? Mathematical Geology, 37, 829-850.

Aitchison J.. (2003) The statistical analysis of compositional data. The Blackburn Press, London.

Andelman S.J. \& Fagan W.F. (2000) Umbrellas and flagships: efficient conservation surrogates or expensive mistakes? Proceedings of the National Academy of Sciences of the United States of America, 97, 5954-5959.

Anselin L., Syabri I., \& Kho Y. (2006) GeoDa: An introduction to spatial data analysis. Geographical Analysis, 38, 5-22.

Auerbach N.A., Wilson K.A., Tulloch A.I.T., Rhodes J.R., Hanson J.O., \& Possingham H.P. (2015) Effects of threat management interactions on conservation priorities. Conservation Biology, 29, $1626-1635$.

Bininda-Emonds O.R.P., Cardillo M., Jones K.E., Macphee R.D.E., Beck R.M.D., Grenyer R., Price S.A., Vos R.A., Gittleman J.L., \& Purvis A. (2007) The delayed rise of present-day mammals. Nature, 446, 507-512.

Brooks T.M., Mittermeier R.A., da Fonseca G.A.B., Gerlach J., Hoffmann M., Lamoreux J.F., Mittermeier C.G., Pilgrim J.D., \& Rodrigues A.S.L. (2006) Global biodiversity conservation priorities. Science, 313, 58-61.

Cardillo M., Mace G.M., Gittleman J.L., \& Purvis A. (2006) Latent extinction risk and the future battlegrounds of mammal conservation. Proceedings of the National Academy of Sciences of the United States of America, 103, 4157-4161.

Cardillo M., Mace G.M., Jones K.E., Bielby J., Bininda-Emonds O.R.P., Sechrest W., Orme C.D.L., 
\& Purvis A. (2005) Multiple causes of high extinction risk in large mammal species. Science, 309, 1239-1241.

Cardillo M., Purvis A., Sechrest W., Gittleman J.L., Bielby J., \& Mace G.M. (2004) Human population density and extinction risk in the world's carnivores. PLOS Biology, 2, 0909-0914.

Carwardine J., O’Connor T., Legge S., Mackey B., Possingham H.P., \& Martin T.G. (2012) Prioritizing threat management for biodiversity conservation. Conservation Letters, 5, 196-204.

Ceballos G., Ehrlich P.R., Barnosky A.D., García A., Pringle R.M., \& Palmer T.M. (2015) Accelerated modern human-induced species losses: Entering the sixth mass extinction. Science Advances, 1, 9-13.

Davidson A.D., Hamilton M.J., Boyer A.G., Brown J.H., \& Ceballos G. (2009) Multiple ecological pathways to extinction in mammals. Proceedings of the National Academy of Science of the United States of America, 106, 10702-10705.

Dobrovolski R., Diniz-Filho J.A.F., Loyola R.D., \& Marco Júnior P. (2011) Agricultural expansion and the fate of global conservation priorities. Biodiversity and Conservation, 20, 2445-2459.

Ellis E.C., Klein Goldewijk K., Siebert S., Lightman D., \& Ramankutty N. (2010) Anthropogenic transformation of the biomes, 1700 to 2000. Global Ecology and Biogeography, 19, 589-606.

Ellis E.C. \& Ramankutty N. (2008) Putting people in the map: anthropogenic biomes of the world. Frontiers in Ecology and the Environment, 6, 439-447.

ESRI (1999) ArcView GIS 3.2, Environmental Systems Research Institute. Redlands, CA, USA. .

ESRI (2008) ArcGIS 9.3, Environmental Systems Research Institute. Redlands, CA, USA. .

Frimpong E.A. \& Angermeier P.L. (2009) Fish Traits: A Database of Ecological and Life-history Traits of Freshwater Fishes of the United States. Fisheries, 34, 487-495.

Fritz S.A., Bininda-Emonds O.R.P., \& Purvis A. (2009) Geographical variation in predictors of mammalian extinction risk : big is bad, but only in the tropics. Ecology Letters, 12, 538-549.

Fry J.M., Fry T.R.L., \& McLaren K.R. (2000) Compositional data analysis and zeros in micro data. Applied Economics, 32, 953-959.

Game E.T., Kareiva P., \& Possingham H.P. (2013) Six Common Mistakes in Conservation Priority Setting. Conservation Biology, 27, 480-485.

González-Suárez M., Gómez A., \& Revilla E. (2013) Which intrinsic traits predict vulnerability to extinction depends on the actual threatening processes. Ecosphere, 4, 1-16.

González-Suárez M., Lucas P.M., \& Revilla E. (2012) Biases in comparative analyses of extinction risk: mind the gap. The Journal of Animal Ecology, 81, 1211-1222.

González-Suárez M. \& Revilla E. (2013) Variability in life-history and ecological traits is a buffer against extinction in mammals. Ecology letters, 16, 242-51.

González-Suárez M. \& Revilla E. (2014) Generalized drivers in the mammalian endangerment process. PLOS ONE, 9, e90292.

Goolsby E.W., Bruggeman J., \& Ane C. (2015) Rphylopars. Phylogenetic comparative tools for missing data within-species variation. $\mathrm{R}$ package version 0.1 .1 .

IUCN (2014) The IUCN Red List of Threatened Species. Version 2014.3. International Union for 
Conservation of Nature, http://www.iucnredlist.org/.

IUCN \& UNEP-WCMC (2015) The World Database on Protected Areas (WDPA). Cambridge, UK., www.protectedplanet.net.

Jennions M. \& Moller A. (2002) How much variance can be explained by ecologists and evolutionary biologists? Oecologia, 132, 492-500.

Jones K.E., Bielby J., Cardillo M., Fritz S.A., O’Dell J., Orme C.D.L., Safi K., Sechrest W., Boakes E.H., Carbone C., Connolly C., Cutis M.J., Foster J.K., Grenyer R., Habib M., Plaster C.A., Price S.A., Rigby E.A., Rist J., Teacher A., Bininda-Emonds O.R.P., Gittleman J.L., Mace G.M., \& Purvis A. (2009) PanTHERIA : a species-level database of life history, ecology , and geography of extant and recently extinct mammals. Ecology, 90, 2648.

Kleyer M., Bekker R.M., Knevel I.C., Bakker J.P., Thompson K., Sonnenschein M., Poschlod P., van Groenendael J.M., Klimeš L., Klimešová J., Klotz S., Rusch G.M., Hermy M., Adriaens D., Boedeltje G., Bossuyt B., Dannemann a., Endels P., Götzenberger L., Hodgson J.G., Jackel aK., Kühn I., Kunzmann D., Ozinga W. a., Römermann C., Stadler M., Schlegelmilch J., Steendam H.J., Tackenberg O., Wilmann B., Cornelissen J.H.C., Eriksson O., Garnier E., \& Peco B. (2008) The LEDA Traitbase: a database of life-history traits of the Northwest European flora. Journal of Ecology, 96, 1266-1274.

Kukkala A.S. \& Moilanen A. (2013) Core concepts of spatial prioritisation in systematic conservation planning. Biological Reviews, 88, 443-464.

Laliberte A.S. \& Ripple W.J. (2004) Range Contractions of North American Carnivores and Ungulates. BioScience, 54, 123-138.

Leroux S.J., Schmiegelow F.K. a, Lessard R.B., \& Cumming S.G. (2007) Minimum dynamic reserves: A framework for determining reserve size in ecosystems structured by large disturbances. Biological Conservation, 138, 464-473.

Di Marco M., Cardillo M., Possingham H.P., Wilson K. a., Blomberg S.P., Boitani L., \& Rondinini C. (2012) A novel approach for global mammal extinction risk reduction. Conservation Letters, 5, 134-141.

Di Marco M. \& Santini L. (2015) Human pressures predict species' geographic range size better than biological traits. Global Change Biology, 21, 2169-2178.

Margules C.R. \& Pressey R.L. (2000) Systematic conservation planning. Nature, 405, 243-53.

Moilanen A., Wilson K.A., \& Possingham H.P. (2009) Spatial conservation prioritization. Quantitative methods \& computational tools. Oxford University Press, Croydon, Great Britain.

Morrison J.C., Sechrest W., Dinerstein E., Wilcove D.S., \& Lamoreux J.F. (2007) Persistence of large mammal faunas as indicators of global human impacts. Journal of Mammalogy, 88, 13631380 .

Myers N. (1989) Threatened biotas: "Hotspots" in tropical forests. Environmentalist, 8, 1-20.

Myers N. (1990) The biodiversity challenge: expanded hotspots analysis. Environmentalist1, 10, $243-256$.

Naidoo R., Balmford A., Ferraro P.J., Polasky S., Ricketts T.H., \& Rouget M. (2006) Integrating economic costs into conservation planning. Trends in Ecology and Evolution, 21, 681-687.

Nakagawa S. \& Freckleton R.P. (2008) Missing inaction: the dangers of ignoring missing data. 
Trends in Ecology and Evolution, 23, 592-596.

Neumann K., Verburg P.H., Stehfest E., \& M??ller C. (2010) The yield gap of global grain production: A spatial analysis. Agricultural Systems, 103, 316-326.

Olson D.M. \& Dinerstein E. (2002) The Global 200: Priority Ecoregions for Global Conservation. Missouri Botanical Garden, 89, 199-224.

Orme D., Freckleton R., Thomas G., Petzoldt T., Fritz S., Isaac N., \& Pearse W. (2013) caper: Comparative Analyses of Phylogenetics and Evolution in R. R package version 0.5.2.

Pekin B.K. \& Pijanowski B.C. (2012) Global land use intensity and the endangerment status of mammal species. Diversity and Distributions, 18, 909-918.

Penone C., Davidson A.D., Shoemaker K.T., Di Marco M., Rondinini C., Brooks T.M., Young B.E., Graham C.H., \& Costa G.C. (2014) Imputation of missing data in life-history traits datasets: which approach performs the best? Methods in Ecology and Evolution, 5, 961-970.

Peres C.A. \& Terborgh J.W. (1995) Amazonian nature reserves: an analysis of the defensibility status of existing conservation units and design criteria for the future. Conservation Biology, 9 , 34-46.

Polaina E., González-Suárez M., \& Revilla E. (2015) Socioeconomic correlates of global mammalian conservation status. Ecosphere, 6, 146.

Purvis A., Gittleman J.L., Cowlishaw G., \& Mace G.M. (2000) Predicting extinction risk in declining species. Proceedings of the Royal Society B, 267, 1947-1952.

R Core Team (2014) R: A language and environment for statistical computing. R Foundation for Statistical Computing, Vienna, Austria.

Roberge J.-M. \& Angelstam P. (2004) Usefulness of the umbrella species concept. Conservation Biology, 18, 76-85.

Sanderson E.W., Jaiteh M., Levy M.A., Redford K.H., Wannebo A. V, \& Woolmer G. (2002) The Human Footprint and the Last of the Wild. BioScience, 52, 891-904.

Tulloch V.J., Tulloch A.I., Visconti P., Halpern B.S., Watson J.E., Evans M.C., Auerbach N. a, Barnes M., Beger M., Chadès I., Giakoumi S., McDonald-Madden E., Murray N.J., Ringma J., \& Possingham H.P. (2015) Why do we map threats? Linking threat mapping with actions to make better conservation decisions. Frontiers in Ecology and the Environment, 13, 91-99.

Underwood E.C., Shaw M.R., Wilson K. a., Kareiva P., Klausmeyer K.R., McBride M.F., Bode M., Morrison S. a., Hoekstra J.M., \& Possingham H.P. (2008) Protecting biodiversity when money matters: Maximizing return on investment. PLOS ONE, 3, e1515.

Vargas A., Sánchez I., Martínez F., Rivas A., Godoy J. a., Roldán E., Simón M. a., Serra R., Pérez M.J., Enseñat C., Delibes M., Aymerich M., Sliwa A., \& Breitenmoser U. (2008) The Iberian lynx Lynx pardinus Conservation Breeding Program. International Zoo Yearbook, 42, 190-198.

Verburg P.H., Neumann K., \& Nol L. (2011) Challenges in using land use and land cover data for global change studies. Global Change Biology, 17, 974-989.

Verde Arregoitia L.D. (2016) Biases, gaps, and opportunities in mammalian extinction risk research. Mammal Review, 46, 17-29.

Watson J.E.M., Grantham H.S., Wilson K. a., \& Possingham H.P. (2011) Systematic Conservation 
Planning: Past, Present and Future. Conservation Biogeography (ed. by R.J. Ladle and R.J. Whittaker), pp. 136-160. John Wiley \& Sons,

Watts M.E., Ball I.R., Stewart R.S., Klein C.J., Wilson K., Steinback C., Lourival R., Kircher L., \& Possingham H.P. (2009) Marxan with Zones: Software for optimal conservation based land- and sea-use zoning. Environmental Modelling and Software, 24, 1513-1521.

Wilson A.C., Fenton B., Malloch G., Boag B., Hubbard S., \& Begg G.S. (2014) Coexisting small mammals display contrasting strategies for tolerating instability in arable habitat. European Journal of Wildlife Research, 60, 811-820.

\section{Supporting Information}

Additional Supporting Information may be found in the online version of this article:

Appendix S1 Species-based models: data.

Appendix S2 Species-based models: complementary results.

Appendix S3 Spatial predictions: data \& results

Figure S1 Biological and ecological data availability.

Figure S2 Linear regression between the imputed values of the intrinsic predictors of vulnerability, based on different numbers of initial traits.

Figure S3 Spatial intrinsic vulnerability calculated as the prediction from the median terrestrial mammal inhabiting each grid cell, and as the mean value of vulnerability per species occurring within a grid cell, according to all alternative models.

Figure S4 Spatial extrinsic vulnerability calculated as the prediction from the proportion of anthromes occurring within each grid cell, and as the mean value of vulnerability per species occurring within a grid cell, according to all alternative models.

Figure S5 Representation of the percentage per grid-cell covered by each of the six anthromes' categories (all species).

Figure S6 Representation of the percentage per grid-cell covered by each of the six anthromes' categories (small species). 
Figure S7 Representation of the percentage per grid-cell covered by each of the six anthromes' categories (large species).

Table S1 Summary of the reference studies.

Table S2 Description of intrinsic traits included in the analyses.

Table S3 Correlations between explanatory variables included in the intrinsic species-based model.

Table S4 Description of anthromes as in Ellis et al. (2010) .

Table S5 Terrestrial mammal species excluded from the anthropogenic models.

Table S6 Correlations between explanatory variables included in the extrinsic species-based model.

Table S7 Correlations between all explanatory variables included in both the intrinsic and extrinsic species-based models.

Table S8 Results of the intrinsic PGLS for all mammals, alternative versions.

Table S9 Results of the anthropogenic PGLS for all mammals, alternative versions.

Table S10 Results of the PGLS including both intrinsic and anthropogenic variables for all mammals.

Table S11 Correlations between intrinsic vulnerability predictions based on the same model, but using different calculations for their spatial representation.

Table S12 Correlations between extrinsic vulnerability predictions based on the same model, but using different calculations for spatial representation.

Table S13 Summary of the available information for the traits employed to calculate intrinsic vulnerability, and numbers of threatened and total mammalian richness, global and segregated by zone category (all species).

Table S14 Summary of the available information for the traits employed to calculate intrinsic vulnerability, and numbers of threatened and total mammalian richness, global and segregated by zone category (small species). 
Table S15 Summary of the available information for the traits employed to calculate intrinsic vulnerability, and numbers of threatened and total mammalian richness, global and segregated by zone category (large species).

As a service to our authors and readers, this journal provides supporting information supplied by the authors. Such materials are peer-reviewed and may be re-organized for online delivery, but are not copy-edited or typeset. Technical support issues arising from supporting information (other than missing files) should be addressed to the authors.

\section{Biosketch}

Ester Polaina is doing her PhD at the Estación Biológica de Doñana-CSIC (Spain). She is interested in the multiple interactions between biodiversity conservation and human development, and how could both be preserved. She is an ardent defender of interdisciplinary study, despite her environmental-ecological training.

Eloy Revilla is a research scientist at Estación Biológica de Doñana-CSIC (Spain) working on the interface between theory in Ecology and Conservation Biology and how they affect our understanding of environmental problems and the management actions we take.

Manuela González-Suárez is a lecturer in ecological modelling at the University of Reading. She is broadly interested in understanding how population dynamics are influenced by a species' ecology and behaviour, and how that knowledge can be used to improve the assessment and management of populations of conservation concern. 
Author contributions: E.P., E.R. and M.G.S conceived the idea for this study. E.P. compiled and analyzed the data. E.P. wrote the paper with significant contributions from E.R. and M.G.S. 


\section{Tables and figures}

Table 1. Results of the species-based phylogenetic generalized least squares (PGLS) models testing the association between intrinsic traits and threat status in terrestrial mammals. Models were fitted for all terrestrial mammals $(A l l)$, small terrestrial mammals (body size $\leq 3 \mathrm{~kg}$. Small), and large terrestrial mammals (body size $>3 \mathrm{~kg}$. Large). Traits were $\log _{10}$-transformed prior to analyses. We report regression coefficient estimates $(\beta)$ with their standard errors $(S E)$, as well as the number the species analyzed in each model $(\mathrm{N})$.

\begin{tabular}{llll}
\hline Traits & \multicolumn{3}{c}{$\beta(\mathrm{SE})$} \\
\cline { 2 - 4 } & All $(\mathrm{N}=981)$ & Small $(\mathrm{N}=678)$ & Large $(\mathrm{N}=303)$ \\
\hline Geographic range & $-0.45(0.028)^{* * *}$ & $-0.31(0.024)^{* * *}$ & $-0.76(0.068)^{* * *}$ \\
Weaning age & $0.26(0.127)^{*}$ & $0.24(0.103)^{*}$ & $-0.02(0.284)$ \\
Body mass & $0.29(0.047)^{* * *}$ & $0.10(0.038)^{* *}$ & $0.55(0.151)^{* * *}$ \\
\hline Adjusted $\mathrm{R}^{2}$ & & 0.25 & 0.23 \\
\hline$* * * \mathrm{p}<0.001 ; * * \mathrm{p}<0.01 ; * \mathrm{p}<0.05 ; \cdot \mathrm{p}<0.1$ & & \\
\end{tabular}

Table 2. Results of the species-based phylogenetic generalized least squares models (PGLS) testing the association between the distribution range anthromes' composition and threat status in terrestrial mammals. Anthromes represent log-transformed ratios between each category and the "dense settlements" category (more detail in the methods). Models were fitted for all terrestrial mammals $(A l l)$, small terrestrial mammals (body size $\leq 3 \mathrm{~kg}$. Small), and large terrestrial mammals (body size $>3$ $\mathrm{kg}$. Large). We report regression coefficient estimates $(\beta)$ with their standard errors $(S E)$, and the number the species analyzed in each model $(\mathrm{N})$.

\begin{tabular}{llll}
\hline Anthromes & \multicolumn{3}{l}{$\beta(\mathrm{SE})$} \\
\cline { 2 - 4 } & All $(\mathrm{N}=3908)$ & Small $(\mathrm{N}=2404)$ & Large $(\mathrm{N}=508)$ \\
\hline Villages & $0.00(0.010)$ & $0.01(0.011)$ & $0.05(0.045)$ \\
Croplands & $0.08(0.012)^{* * *}$ & $0.05(0.014)^{* * * *}$ & $0.10(0.049) \cdot$ \\
Rangelands & $0.00(0.009)$ & $0.10(0.011)^{* * *}$ & $-0.10(0.030)^{* *}$ \\
Semi-natural lands & $0.22(0.012)^{* * *}$ & $0.12(0.015)^{* * *}$ & $0.54(0.051)^{* * *}$ \\
Wildlands & $-0.17(0.009)^{* * *}$ & $-0.18(0.012)^{* * *}$ & $-0.24(0.034)^{* * *}$ \\
\hline Adjusted $\mathrm{R}^{2}$ & 0.13 & 0.11 & 0.24 \\
\hline$* * * \mathrm{p}<0.001 ; * * \mathrm{p}<0.01 ; * \mathrm{p}<0.05 ; \cdot \mathrm{p}<0.1$ & &
\end{tabular}




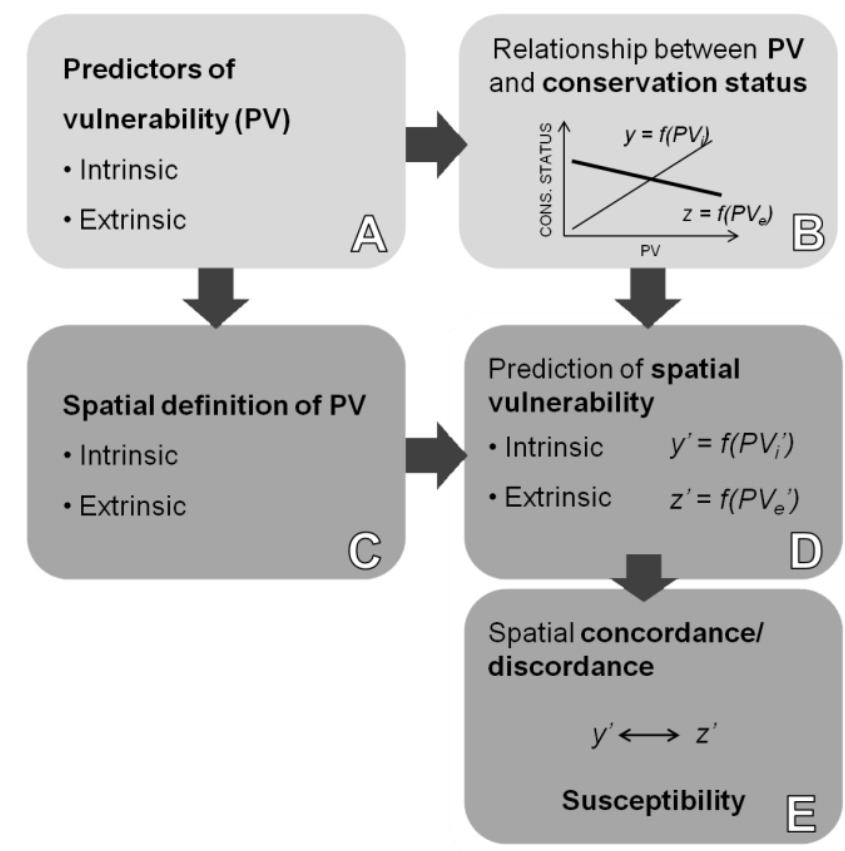

Figure 1. Summary of the proposed methodology to prioritize conservation actions. Light grey boxes indicate steps to be taken at the species level; dark grey boxes show steps at the spatial level. 

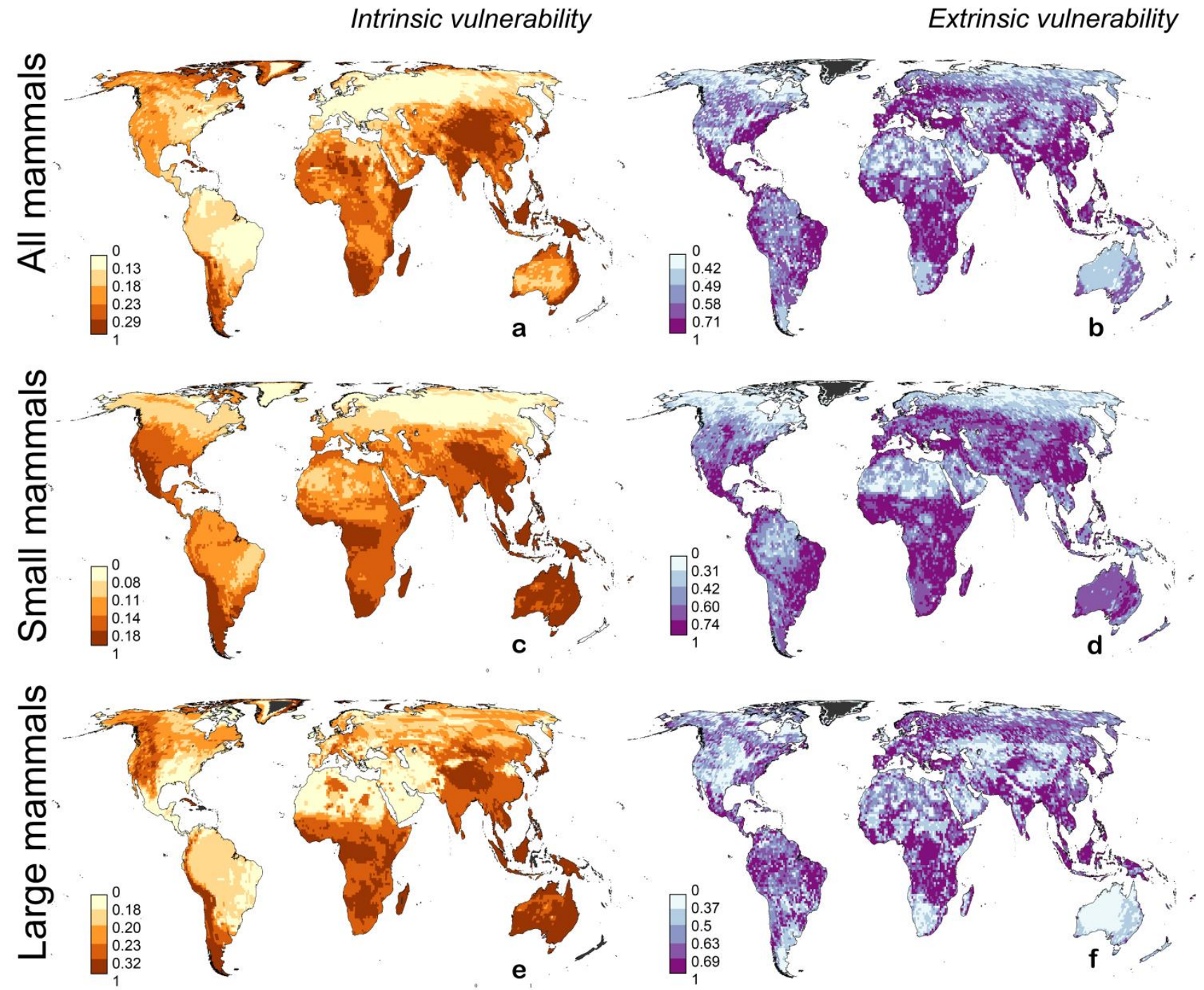

Figure 2. Predicted intrinsic $(a)$ and extrinsic $(b)$ vulnerability based on all terrestrial mammal species, and separately for small (body size $\leq 3 \mathrm{~kg} ; c \& d$ ) and large species ( $>3 \mathrm{~kg} ; e \& f$ ). All predictions (of continuous Red List Status) are standardized between 0-1 to facilitate comparison. Legend categories are based on quantiles. More intense colors indicate higher vulnerability. Black areas indicate no data. 


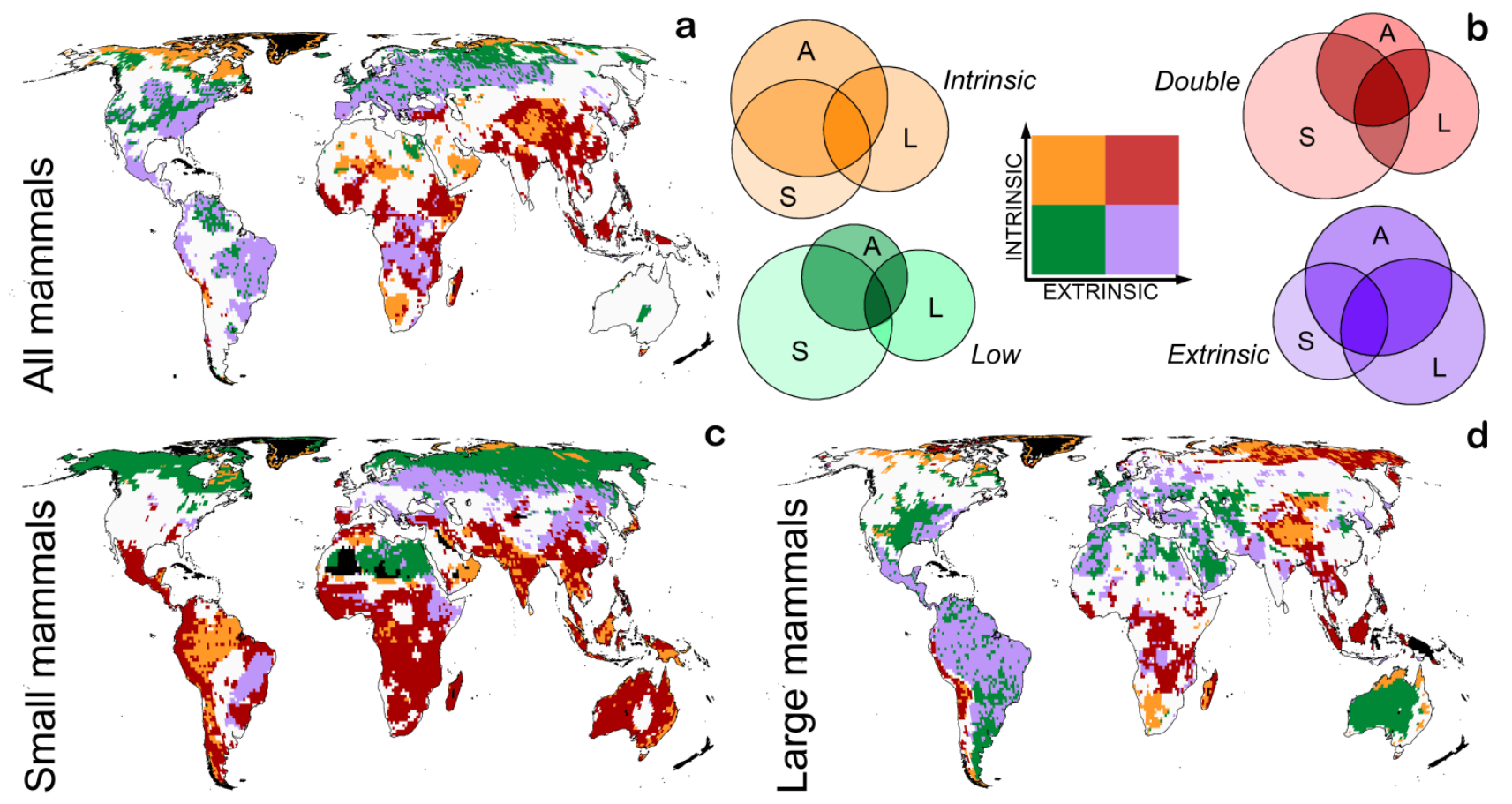

Figure 3. Zonation based on the concordance or discordance between intrinsic and extrinsic vulnerability, for all terrestrial mammal species $(a)$, and separately considering small (body size $\leq 3 \mathrm{~kg} ; c)$ and large species $(>3 \mathrm{~kg} ; d)$. The four types of zone (double-, low-, intrinsic- and extrinsicsusceptibility) are delimited by calculating bivariate local Moran's I. Panel $b$ shows Venn diagrams (one for each type of zone) of the spatial agreement among predictions based on all mammals $(A)$, only small $(S)$ and only large species $(L)$. The legend in panel $b$ applies for both the maps and the diagrams; horizontal axis represents extrinsic vulnerability and vertical axis, intrinsic vulnerability. 


\section{Supporting Information}

\section{Putting susceptibility on the map to improve conservation planning, an example with terrestrial mammals}

Polaina, Ester ${ }^{\mathrm{a}}$, Revilla, Eloy ${ }^{\mathrm{a}}$, González-Suárez, Manuela ${ }^{\mathrm{a}, \mathrm{b}}$

${ }^{a}$ Department of Conservation Biology, Estación Biológica de Doñana-CSIC, Calle Américo Vespucio s/n, 41092 Sevilla, Spain. ${ }^{\mathrm{b}}$ School of Biological Sciences, University of Reading, Whiteknights, Reading, RG6 $6 \mathrm{AS}, \mathrm{UK}$

Corresponding author: Ester Polaina (e.polaina@ebd.csic.es)

\section{Appendix S1. Species-based models: data}

Intrinsic predictors of vulnerability

From the eleven consulted articles, seven of them considered exclusively biological/ecological variables describing species' traits (Morrow \& Fricke, 2004; Davidson et al., 2009; Liow et al., 2009; González-Suárez \& Revilla, 2013; Verde Arregoitia et al., 2013; Chen, 2014; Polishchuk et al., 2015). Three others included species' traits and additionally explored the role of human variables and environmental indicators describing conditions within species geographic range (Cardillo et al., 2005, 2008; Jetz \& Freckleton, 2015). The last study evaluated environmental and socioeconomic characteristics within ecoregions, predicting risk levels by ecoregion instead of for specific species (Fritz et al., 2009). Studies focusing on a certain subgroup of mammals, or not covering the whole Earth surface were discarded, based on the review in Verde Arregoitia, (2016) .

Table S1. Summary of the reference studies $(\mathrm{N}=11)$. Variables found to have a significant effect on the response variable (IUCN global threat status, converted to numeric) are in bold.

\begin{tabular}{llll}
\hline Reference & Statistic model & Intrinsic variables & Other variables \\
\hline Cardillo et & Multiple & - Age eyes' opening & - 5th percentile of HPD \\
al. 2005 & regression on & - Age first breeding & - External threat index \\
& phylogenetically & - Body mass & - Human population density \\
& independent & - Diet & (HPD) \\
& contrasts & - Diurnality & - Latitude \\
& & - Geographic range & \\
\hline
\end{tabular}




\begin{tabular}{|c|c|c|c|}
\hline Reference & Statistic model & Intrinsic variables & Other variables \\
\hline & & $\begin{array}{l}\text { - Gestation length } \\
\text { - Habitat mode } \\
\text { - Home range } \\
\text { - Interbirth interval } \\
\text { - Island endemic } \\
\text { - Litter size } \\
\text { - Litters per year } \\
\text { - Neonatal body mass } \\
\text { - Population density } \\
\text { - Population size } \\
\text { - Sexual maturity age } \\
\text { - Social group size } \\
\text { - Terrestriality } \\
\text { - Trophic level } \\
\text { - Weaning age }\end{array}$ & \\
\hline $\begin{array}{l}\text { Cardillo et } \\
\text { al. } 2008\end{array}$ & $\begin{array}{l}\text { GLM (with } \\
\text { previous } \\
\text { phylogenetically } \\
\text { independent } \\
\text { contrasts) }\end{array}$ & $\begin{array}{l}\text { - Age eyes' opening } \\
\text { - Age first breeding } \\
\text { - Body mass } \\
\text { - Diet } \\
\text { - Diurnality } \\
\text { - Geographic range } \\
\text { - Gestation length } \\
\text { - Habitat mode } \\
\text { - Home range } \\
\text { - Interbirth interval } \\
\text { - Island endemic } \\
\text { - Litter size } \\
\text { - Litters per year } \\
\text { - Neonatal body mass } \\
\text { - Population density } \\
\text { - Population size } \\
\text { - Sexual maturity age } \\
\text { - Social group size } \\
\text { - Terrestriality } \\
\text { - Trophic level } \\
\text { - Weaning age }\end{array}$ & $\begin{array}{l}\text { - Human population density } \\
\text { (HPD) } \\
\text { - } 5 \text { th percentile of HPD } \\
\text { - External threat index } \\
\text { - } \text { Latitude }\end{array}$ \\
\hline Chen 2014 & $\begin{array}{l}\text { Polyserial } \\
\text { correlations }\end{array}$ & $\begin{array}{l}\text { - Geographic range } \\
\text { - Areal size of high suitable } \\
\text { habitat } \\
\text { - Areal size of intermediate } \\
\text { suitable habitat } \\
\text { - Areal size of low suitable }\end{array}$ & \\
\hline
\end{tabular}




\begin{tabular}{|c|c|c|c|}
\hline Reference & Statistic model & Intrinsic variables & Other variables \\
\hline & & habitat & \\
\hline $\begin{array}{l}\text { Davidson et } \\
\text { al. } 2009\end{array}$ & $\begin{array}{l}\text { Decission-tree } \\
\text { models }\end{array}$ & $\begin{array}{l}\text { - Body mass } \\
\text { - Diurnality } \\
\text { - Geographic range } \\
\text { - Habitat mode } \\
\text { - Home range } \\
\text { - Island endemic } \\
\text { - Population density } \\
\text { - Social group size } \\
\text { - Sociality } \\
\text { - Speed of life history } \\
\text { - Trophic level }\end{array}$ & \\
\hline $\begin{array}{l}\text { Fritz et al. } \\
2009\end{array}$ & $\begin{array}{l}\text { Phylogenetic } \\
\text { generalized } \\
\text { linear model }\end{array}$ & $\begin{array}{l}\text { - Body mass } \\
\text { - Geographic range } \\
\text { - Gestation length } \\
\text { - Population density } \\
\text { - Weaning age }\end{array}$ & $\begin{array}{l}\text { (Ecoregional scale) } \\
\text { - Ecoregion area } \\
\text { - Habitat heterogeneity } \\
\text { - Historic agriculture index } \\
\text { - Mean annual actual } \\
\text { evapotranspiration } \\
\text { - Mean elevation } \\
\text { - Mean gross domestic product } \\
\text { - Mean human appropriation of } \\
\text { net primary productivity } \\
\text { - Mean human influence index } \\
\text { - Mean human population } \\
\text { density } \\
\text { - Proportion of cropland in } 2000 \\
\text { - Proportion of urban land cover } \\
\text { in } 2000\end{array}$ \\
\hline $\begin{array}{l}\text { González- } \\
\text { Suárez \& } \\
\text { Revilla } \\
2013\end{array}$ & $\begin{array}{l}\text { Taxonomically } \\
\text { informed } \\
\text { GLMM }\end{array}$ & $\begin{array}{l}\text { - Body mass } \\
\text { - Body mass variability } \\
\text { - Geographic range } \\
\text { - Litter size } \\
\text { - Litter size variability } \\
\text { - Population density } \\
\text { - Population density variability } \\
\text { - Sexual maturity age } \\
\text { - Sexual maturity age variability } \\
\text { - Weaning age } \\
\text { - Weaning age variability }\end{array}$ & \\
\hline $\begin{array}{l}\text { Jetz \& } \\
\text { Freckleton }\end{array}$ & $\begin{array}{l}\text { Phlyogenetic } \\
\text { generalized }\end{array}$ & $\begin{array}{l}\text { - Body mass } \\
\text { - Geographical range }\end{array}$ & - Human encroachment \\
\hline
\end{tabular}




\begin{tabular}{|c|c|c|}
\hline Reference & Statistic model & Intrinsic variables \\
\hline 2015 & $\begin{array}{l}\text { least-squares } \\
\text { (PGLS) }\end{array}$ & \\
\hline $\begin{array}{l}\text { Liow et al. } \\
2009\end{array}$ & $\begin{array}{l}\text { Phylogenetic } \\
\text { independent } \\
\text { contrasts }\end{array}$ & $\begin{array}{l}\text { - Body mass } \\
\text { - Geographic range } \\
\text { - SLOH (sleeping or hide) } \\
\text { behavior } \\
\text { - } \text { Trophic level }\end{array}$ \\
\hline $\begin{array}{l}\text { Morrow \& } \\
\text { Fricke } 2004\end{array}$ & $\begin{array}{l}\text { Comparative } \\
\text { analysis of } \\
\text { independent } \\
\text { contrasts } \\
\text { (CAIC) }\end{array}$ & $\begin{array}{l}\text { - Sexual dimorphysm } \\
\text { - Testes size }\end{array}$ \\
\hline $\begin{array}{l}\text { Polishchuk } \\
\text { et al. } 2015\end{array}$ & $\begin{array}{l}\text { Mixed-effects } \\
\text { logistic } \\
\text { regression } \\
\text { model }\end{array}$ & $\begin{array}{l}\text { - Body mass } \\
\text { - Nonsynonymus to synonymus } \\
\text { sustitutions (Ka / Ks) }\end{array}$ \\
\hline $\begin{array}{l}\text { Verde } \\
\text { Arregoitia et } \\
\text { al. } 2013\end{array}$ & $\begin{array}{l}\text { phylogenetic } \\
\text { generalized } \\
\text { linear mixed } \\
\text { model } \\
\text { (PGLMM) }\end{array}$ & $\begin{array}{l}\text { - Body mass } \\
\text { - Net diversification rate }\end{array}$ \\
\hline
\end{tabular}




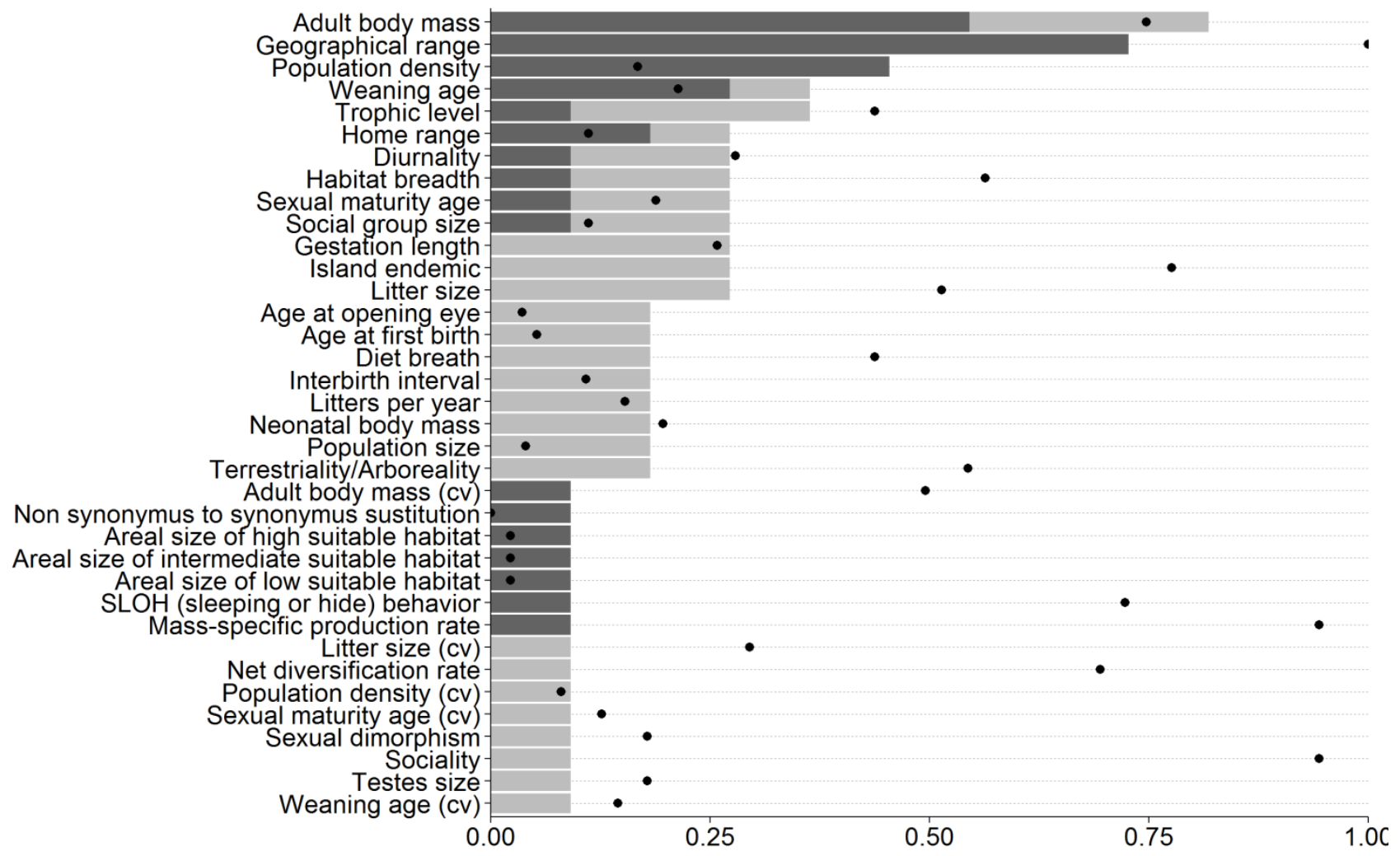

Figure S1. Biological and ecological data availability, and frequency of association with extinction risk in terrestrial mammals. Length of bars represent the proportion of studies in which variables were considered $(\max =11)$. Dark filling represents studies in which variables significantly related to the threat status of mammals. Light filling represents studies in which variables did not relate to the threat status of mammals. Black circles symbolize the proportion of species with data for that trait in the database PanTHERIA (Jones et al., 2009) or self-obtained data employed in the cited studies, from the 4668 terrestrial mammals with data for at least one trait in PanTHERIA. 
Table S2. Description of intrinsic traits included in the analyses. $N$, number of terrestrial species with available estimates.

\begin{tabular}{|c|c|c|c|}
\hline Trait & Definition provided in the data source reference & $\mathrm{N}$ & Data source \\
\hline $\begin{array}{l}\text { Adult body mass } \\
\text { (g) }\end{array}$ & $\begin{array}{l}\text { Mass of adult (or age unspecified) live or freshly-killed specimens } \\
\text { (excluding pregnant females) using captive, wild, provisioned, or } \\
\text { unspecified populations; male, female, or sex unspecified } \\
\text { individuals; primary, secondary, or extrapolated sources; all } \\
\text { measures of central tendency; in all localities. }\end{array}$ & 3427 & $\begin{array}{l}\text { PanTHERIA } \\
\text { (Jones et al, 2009) }\end{array}$ \\
\hline $\begin{array}{l}\text { Geographical range } \\
\left(\mathrm{km}^{2}\right)\end{array}$ & $\begin{array}{l}\text { Calculated using IUCN distribution data with a cylindrical equal- } \\
\text { area projection (ArcGIS 9.3). }\end{array}$ & 4668 & $\begin{array}{l}\text { Spatial data of the } \\
\text { IUCN Red List } \\
\text { (IUCN, 2014) }\end{array}$ \\
\hline $\begin{array}{l}\text { Population density } \\
\left(\mathrm{n} / \mathrm{km}^{2}\right)\end{array}$ & $\begin{array}{l}\text { Number of individuals per square kilometer, estimated with either } \\
\text { direct, indirect or unspecified counts, measured in any area size } \\
\text { within a human, ecological or unspecified boundary, over any } \\
\text { duration of time, using non-captive, non-provisioned populations; } \\
\text { male, female, or sex unspecified individuals; primary, secondary, or } \\
\text { extrapolated sources; all measures of central tendency; in all } \\
\text { localities. }\end{array}$ & 936 & $\begin{array}{l}\text { PanTHERIA } \\
\text { (Jones et al, 2009) }\end{array}$ \\
\hline $\begin{array}{l}\text { Weaning age } \\
\text { (days) }\end{array}$ & $\begin{array}{l}\text { Age when primary nutritional dependency on the mother ends and } \\
\text { independent foraging begins to make a major contribution to the } \\
\text { offspring's energy requirements, measured as either } \\
\text { weaning/lactation length, nutritionally independent, first solid food, } \\
\text { last observed nursing, age at first flight (bats only), age at pouch exit } \\
\text { or length of teat Attachment (marsupials only) or unspecified } \\
\text { definition, using captive, wild, provisioned, or unspecified } \\
\text { populations; male, female, or sex unspecified individuals; primary, } \\
\text { secondary, or extrapolated sources; all measures of central tendency; } \\
\text { in all localities. }\end{array}$ & 1095 & $\begin{array}{l}\text { PanTHERIA } \\
\text { (Jones et al, 2009) }\end{array}$ \\
\hline
\end{tabular}

Table S3. Correlations between explanatory variables included in the intrinsic species-based model. Spearman's $\rho$ values and sample sizes (in brackets) are provided.

\begin{tabular}{lrrrr}
\hline & Population density & Geographic range & Weaning age \\
\hline Geographic range & $-0.14(902)$ & & & \\
Weaning age & $-0.57(568)$ & -0.11 & $(1056)$ & \\
Body mass & $-0.76(899)$ & $-0.08 \quad(3088)$ & $0.61 \quad(1041)$ \\
\hline
\end{tabular}


Table S4. Description of anthromes as in Ellis et al. (2010) .

\begin{tabular}{|c|c|c|}
\hline Group & Biomes included & Description \\
\hline Dense & Urban & Urban and other dense settlements \\
\hline settlements & Mixed ettlements & Dense built environments with very high populations \\
\hline \multirow[t]{4}{*}{ Villages } & Rice villages & Villages dominated by paddy rice \\
\hline & Irrigated villages & Villages dominated by irrigated crops \\
\hline & Rainfed villages & Villages dominated by rainfed agriculture \\
\hline & Pastoral villages & Villages dominated by rangeland \\
\hline \multirow[t]{4}{*}{ Croplands } & $\begin{array}{l}\text { Residential irrigated } \\
\text { croplands }\end{array}$ & Irrigated cropland with substantial human populations \\
\hline & $\begin{array}{l}\text { Residential rainfed } \\
\text { croplands }\end{array}$ & Rainfed croplands with substantial human populations \\
\hline & Populated rainfed cropland & $\begin{array}{l}\text { Croplands with significant human populations, a mix of irrigated and } \\
\text { rainfed crops }\end{array}$ \\
\hline & Remote croplands & Croplands without significant populations \\
\hline \multirow[t]{3}{*}{ Rangeland } & Residential rangelands & Rangelands with substantial human populations \\
\hline & Populated rangelands & Rangelands with significant human populations \\
\hline & Remote rangelands & Rangelands without significant human populations \\
\hline Seminatural & Residential woodlands & Forest regions with minor land use and substantial populations \\
\hline \multirow[t]{3}{*}{ lands } & Populated woodlands & Forest regions with minor land use and significant populations \\
\hline & Remote woodlands & Forest regions with minor land use without significant populations \\
\hline & $\begin{array}{l}\text { Inhabited treeless and } \\
\text { barren lans }\end{array}$ & $\begin{array}{l}\text { Regions without natural tree cover having ony minor land use and a range } \\
\text { of populations }\end{array}$ \\
\hline \multirow[t]{2}{*}{ Wildlands } & Wild woodlands & Forests and savanna \\
\hline & $\begin{array}{l}\text { Wild treeless and barren } \\
\text { lands }\end{array}$ & $\begin{array}{l}\text { Regions without natural tree cover (grasslands, shrublands, tundra, desert } \\
\text { and barrend lands) }\end{array}$ \\
\hline
\end{tabular}

Table S5. Terrestrial mammal species excluded from the anthropogenic models (PGLS) due to topological errors (their geographic ranges were covered by anthromes in less than $95 \%$ of their total surface; $\mathrm{N}=86$ ). $T h r$,. indicates if the species is thereatened (1) or not (0); the following columns represent the overlapping proportion of the geographic range with each anthrome class: $D$, dense settlements; $V$, villages; $C$, croplands; $R$, rangelands; S.N., semi-natural lands; $W$, wildlands; Addition, of all previous classes.

\begin{tabular}{lcrrrrrrr}
\hline Species name & Thr. & D & V & C & R & S.N. & W & Addition \\
\hline Abrothrix hershkovitzi & 0 & 0 & 0 & 0 & 0 & 0 & 0.92 & 0.92 \\
Acerodon humilis & 1 & 0.22 & 0 & 0.02 & 0 & 0.71 & 0 & 0.95
\end{tabular}




\begin{tabular}{|c|c|c|c|c|c|c|c|c|}
\hline Species name & Thr. & $\mathrm{D}$ & $\mathrm{V}$ & $\mathrm{C}$ & $\mathrm{R}$ & S.N. & $\mathrm{W}$ & Addition \\
\hline Aethomys kaiseri & 0 & 0.01 & 0.05 & 0.11 & 0.34 & 0.42 & 0.02 & 0.95 \\
\hline Allactodipus bobrinskii & 0 & 0 & 0.01 & 0.02 & 0.74 & 0.01 & 0.12 & 0.90 \\
\hline Alopex lagopus & 0 & 0 & 0 & 0 & 0.01 & 0.06 & 0.82 & 0.89 \\
\hline Ardops nichollsi & 0 & 0.03 & 0 & 0.42 & 0.05 & 0.44 & 0 & 0.95 \\
\hline Babyrousa togeanensis & 1 & 0 & 0 & 0 & 0 & 0.92 & 0 & 0.92 \\
\hline Bettongia lesueur & 0 & 0 & 0 & 0 & 0.24 & 0.14 & 0 & 0.39 \\
\hline Brachyphylla cavernarum & 0 & 0.41 & 0.03 & 0.21 & 0.06 & 0.25 & 0 & 0.95 \\
\hline Chilonatalus tumidifrons & 0 & 0 & 0 & 0 & 0 & 0.5 & 0.41 & 0.91 \\
\hline Chiroderma improvisum & 1 & 0.01 & 0 & 0.37 & 0.16 & 0.4 & 0 & 0.94 \\
\hline Crocidura jacksoni & 0 & 0.02 & 0.2 & 0.23 & 0.4 & 0.06 & 0.02 & 0.93 \\
\hline Crocidura orii & 1 & 0.12 & 0 & 0 & 0 & 0.82 & 0 & 0.94 \\
\hline Crocidura watasei & 0 & 0.2 & 0.04 & 0.03 & 0 & 0.63 & 0 & 0.90 \\
\hline Dasyprocta coibae & 1 & 0 & 0 & 0 & 0 & 0.07 & 0.5 & 0.57 \\
\hline Dicrostonyx groenlandicus & 0 & 0 & 0 & 0 & 0 & 0.02 & 0.9 & 0.92 \\
\hline Dicrostonyx torquatus & 0 & 0 & 0 & 0 & 0 & 0.06 & 0.88 & 0.94 \\
\hline Dipodomys insularis & 1 & 0 & 0 & 0 & 0.05 & 0.51 & 0 & 0.57 \\
\hline Dipodomys margaritae & 1 & 0 & 0 & 0 & 0 & 0 & 0.03 & 0.03 \\
\hline Dobsonia pannietensis & 0 & 0.08 & 0 & 0 & 0 & 0.84 & 0.02 & 0.95 \\
\hline Echymipera davidi & 1 & 0 & 0 & 0 & 0 & 0.76 & 0 & 0.76 \\
\hline Emballonura semicaudata & 1 & 0 & 0 & 0.02 & 0 & 0.05 & 0.25 & 0.32 \\
\hline Enhydra lutris & 1 & 0 & 0 & 0 & 0 & 0.01 & 0.02 & 0.03 \\
\hline Geocapromys ingrahami & 1 & 0 & 0 & 0 & 0 & 0 & 0 & 0 \\
\hline Hippocamelus bisulcus & 1 & 0 & 0 & 0 & 0.34 & 0.15 & 0.43 & 0.93 \\
\hline Lagorchestes hirsutus & 1 & 0 & 0 & 0 & 0 & 0 & 0 & 0 \\
\hline Lemmus sibiricus & 0 & 0 & 0 & 0 & 0 & 0.03 & 0.9 & 0.93 \\
\hline Leontopithecus caissara & 1 & 0 & 0 & 0.2 & 0.5 & 0.06 & 0 & 0.76 \\
\hline Leporillus conditor & 1 & 0 & 0 & 0 & 0 & 0 & 0 & 0 \\
\hline Lepus arcticus & 0 & 0 & 0 & 0 & 0 & 0.04 & 0.82 & 0.86 \\
\hline Lepus flavigularis & 1 & 0 & 0 & 0.39 & 0.48 & 0 & 0 & 0.87 \\
\hline Lepus insularis & 0 & 0 & 0 & 0 & 0.04 & 0 & 0 & 0.04 \\
\hline Lontra felina & 1 & 0 & 0 & 0 & 0.04 & 0.05 & 0.09 & 0.18 \\
\hline Lophuromys medicaudatus & 1 & 0.13 & 0.36 & 0.13 & 0.09 & 0.24 & 0 & 0.94 \\
\hline Lophuromys woosnami & 0 & 0.06 & 0.54 & 0.12 & 0.06 & 0.13 & 0.02 & 0.93 \\
\hline Melomys caurinus & 1 & 0.22 & 0 & 0.02 & 0 & 0.71 & 0 & 0.95 \\
\hline Melomys talaudium & 1 & 0.22 & 0 & 0.02 & 0 & 0.71 & 0 & 0.95 \\
\hline Mesocapromys angelcabrerai & 1 & 0 & 0 & 0.37 & 0 & 0 & 0 & 0.37 \\
\hline Microtus abbreviatus & 0 & 0 & 0 & 0 & 0 & 0 & 0.32 & 0.32 \\
\hline Miniopterus fuscus & 1 & 0.18 & 0.06 & 0.03 & 0 & 0.67 & 0 & 0.94 \\
\hline Mirimiri acrodonta & 1 & 0 & 0 & 0 & 0 & 0 & 0.06 & 0.06 \\
\hline Mormopterus acetabulosus & 1 & 0.11 & 0.03 & 0.26 & 0 & 0.33 & 0 & 0.72 \\
\hline Mus triton & 0 & 0.02 & 0.15 & 0.14 & 0.39 & 0.24 & 0.01 & 0.95 \\
\hline Mustela erminea & 0 & 0.01 & 0.02 & 0.17 & 0.12 & 0.15 & 0.48 & 0.95 \\
\hline Myonycteris brachycephala & 1 & 0 & 0 & 0.2 & 0 & 0.74 & 0 & 0.94 \\
\hline Myotis vivesi & 1 & 0 & 0 & 0 & 0.69 & 0.14 & 0.01 & 0.83 \\
\hline
\end{tabular}




\begin{tabular}{|c|c|c|c|c|c|c|c|c|}
\hline Species name & Thr. & $\mathrm{D}$ & $\mathrm{V}$ & $\mathrm{C}$ & $\mathrm{R}$ & S.N. & $\mathrm{W}$ & Addition \\
\hline Myotis yanbarensis & 1 & 0.21 & 0 & 0 & 0 & 0.63 & 0 & 0.84 \\
\hline Mysateles gundlachi & 1 & 0 & 0 & 0.27 & 0.01 & 0.49 & 0.06 & 0.84 \\
\hline Mysateles meridionalis & 1 & 0 & 0 & 0 & 0 & 0.67 & 0.18 & 0.85 \\
\hline Natalus primus & 1 & 0 & 0.02 & 0.4 & 0.01 & 0.43 & 0.06 & 0.91 \\
\hline Nesoryzomys swarthi & 1 & 0 & 0 & 0 & 0 & 0 & 0.51 & 0.51 \\
\hline Notomys aquilo & 1 & 0 & 0 & 0 & 0.77 & 0.01 & 0.02 & 0.8 \\
\hline Octodon pacificus & 1 & 0 & 0 & 0 & 0 & 0.9 & 0 & 0.9 \\
\hline Oligoryzomys magellanicus & 0 & 0 & 0 & 0 & 0.58 & 0.03 & 0.32 & 0.93 \\
\hline Ovibos moschatus & 0 & 0 & 0 & 0 & 0 & 0.03 & 0.85 & 0.89 \\
\hline Peromyscus keeni & 0 & 0.01 & 0 & 0.01 & 0.02 & 0.25 & 0.65 & 0.94 \\
\hline Peromyscus pseudocrinitus & 1 & 0 & 0 & 0 & 0.92 & 0 & 0 & 0.92 \\
\hline Phyllomys thomasi & 1 & 0 & 0 & 0 & 0.76 & 0.15 & 0 & 0.91 \\
\hline Pipistrellus maderensis & 1 & 0.03 & 0 & 0.08 & 0.64 & 0.1 & 0 & 0.85 \\
\hline Potorous gilbertii & 1 & 0 & 0 & 0 & 0.04 & 0 & 0 & 0.04 \\
\hline Pseudomys fieldi & 1 & 0 & 0 & 0 & 0 & 0 & 0 & 0 \\
\hline Pteropus faunulus & 1 & 0 & 0 & 0.15 & 0 & 0.36 & 0 & 0.5 \\
\hline Pteropus fundatus & 1 & 0.01 & 0 & 0 & 0 & 0.68 & 0 & 0.69 \\
\hline Pteropus livingstonii & 1 & 0.14 & 0 & 0.73 & 0 & 0.01 & 0 & 0.88 \\
\hline Pteropus melanotus & 1 & 0 & 0.23 & 0.52 & 0 & 0.16 & 0 & 0.91 \\
\hline Pteropus niger & 1 & 0.12 & 0 & 0.15 & 0 & 0 & 0 & 0.27 \\
\hline Pteropus nitendiensis & 1 & 0 & 0 & 0.57 & 0 & 0 & 0 & 0.57 \\
\hline Pteropus pohlei & 1 & 0.03 & 0 & 0.02 & 0 & 0.9 & 0 & 0.95 \\
\hline Pteropus rennelli & 1 & 0 & 0 & 0 & 0 & 0.78 & 0.01 & 0.79 \\
\hline Pteropus seychellensis & 0 & 0.06 & 0.07 & 0.53 & 0.05 & 0.03 & 0.14 & 0.87 \\
\hline Rattus simalurensis & 1 & 0 & 0.07 & 0.33 & 0 & 0.03 & 0 & 0.43 \\
\hline Rattus stoicus & 1 & 0 & 0 & 0.61 & 0 & 0.18 & 0 & 0.79 \\
\hline Rhinolophus ruwenzorii & 1 & 0.03 & 0.37 & 0.23 & 0.11 & 0.2 & 0.01 & 0.95 \\
\hline Sorex jacksoni & 0 & 0 & 0 & 0 & 0 & 0.04 & 0.83 & 0.87 \\
\hline Stenoderma rufum & 1 & 0.63 & 0.04 & 0.05 & 0.06 & 0.14 & 0 & 0.94 \\
\hline Sturnira thomasi & 1 & 0.01 & 0 & 0.37 & 0.16 & 0.4 & 0 & 0.94 \\
\hline Sylvilagus mansuetus & 0 & 0 & 0 & 0 & 0.13 & 0.59 & 0 & 0.72 \\
\hline Sylvisorex johnstoni & 0 & 0.02 & 0.1 & 0.11 & 0.17 & 0.36 & 0.17 & 0.94 \\
\hline Tadarida bemmeleni & 0 & 0.02 & 0.2 & 0.2 & 0.32 & 0.14 & 0.03 & 0.91 \\
\hline Tadarida bregullae & 1 & 0 & 0 & 0.05 & 0 & 0.83 & 0.03 & 0.91 \\
\hline Tadarida tomensis & 1 & 0.08 & 0 & 0.25 & 0 & 0.6 & 0 & 0.94 \\
\hline Taterillus lacustris & 0 & 0 & 0.03 & 0.86 & 0.01 & 0.05 & 0 & 0.95 \\
\hline Tokudaia tokunoshimensis & 1 & 0 & 0 & 0 & 0 & 0.83 & 0 & 0.83 \\
\hline Tragulus nigricans & 1 & 0 & 0 & 0.17 & 0 & 0.63 & 0 & 0.80 \\
\hline Urocyon littoralis & 1 & 0 & 0 & 0.05 & 0.21 & 0 & 0.13 & 0.40 \\
\hline Ursus maritimus & 1 & 0 & 0 & 0 & 0 & 0.02 & 0.26 & 0.28 \\
\hline
\end{tabular}


Table S6. Correlations between explanatory variables included in the extrinsic species-based model $(\mathrm{N}=4348)$. Spearman's $\rho$ values are provided.

\begin{tabular}{|c|c|c|c|c|c|}
\hline & Urban & Villages & Croplands & Rangelands & Semi-natural lands \\
\hline Villages & 0.21 & & & & \\
\hline Croplands & 0.03 & 0.14 & & & \\
\hline Rangelands & -0.24 & -0.32 & -0.30 & & \\
\hline Semi-natural lands & 0.01 & -0.19 & -0.28 & -0.60 & \\
\hline Wildlands & -0.14 & -0.25 & -0.29 & -0.22 & 0.04 \\
\hline
\end{tabular}

Table S7. Correlations between all explanatory variables included in both the intrinsic and extrinsic speciesbased models (only species with information for both types of variables are considered). Spearman's $\rho$ values and sample sizes (in brackets) are provided.

\begin{tabular}{|c|c|c|c|c|c|c|c|c|c|}
\hline & Urban & Villages & Croplands & Rangelands & $\begin{array}{l}\text { Semi-natural } \\
\text { lands }\end{array}$ & Wildlands & $\begin{array}{l}\text { Geographic } \\
\text { range }\end{array}$ & Body mass & $\begin{array}{l}\text { Populaion } \\
\text { density }\end{array}$ \\
\hline Villages & $\begin{array}{r}0.53 \\
(4339)\end{array}$ & & & & & & & & \\
\hline Croplands & $\begin{array}{r}0.39 \\
(4339)\end{array}$ & $\begin{array}{r}0.49 \\
(4339)\end{array}$ & & & & & & & \\
\hline Rangelands & $\begin{array}{r}-0.33 \\
(4339)\end{array}$ & $\begin{array}{r}-0.20 \\
(4339)\end{array}$ & $\begin{array}{r}-0.20 \\
(4339)\end{array}$ & & & & & & \\
\hline $\begin{array}{l}\text { Semi-natural } \\
\text { lands }\end{array}$ & $\begin{array}{r}0.18 \\
(4339)\end{array}$ & $\begin{array}{r}-0.06 \\
(4339)\end{array}$ & $\begin{array}{r}-0.20 \\
(4339)\end{array}$ & $\begin{array}{r}-0.59 \\
(4339)\end{array}$ & & & & & \\
\hline Wildlands & $\begin{array}{r}-0.10 \\
(4339)\end{array}$ & $\begin{array}{r}-0.31 \\
(4339)\end{array}$ & $\begin{array}{r}-0.26 \\
(4339)\end{array}$ & $\begin{array}{r}-0.08 \\
(4339)\end{array}$ & $\begin{array}{r}0.30 \\
(4339)\end{array}$ & & & & \\
\hline $\begin{array}{l}\text { Geographic } \\
\text { range }\end{array}$ & $\begin{array}{r}0.11 \\
(4339)\end{array}$ & $\begin{array}{r}0.12 \\
(4339)\end{array}$ & $\begin{array}{r}0.11 \\
(4339)\end{array}$ & $\begin{array}{r}0.15 \\
(4339)\end{array}$ & $\begin{array}{r}0 \\
(4339)\end{array}$ & $\begin{array}{r}0.53 \\
(4339)\end{array}$ & & & \\
\hline Body mass & $\begin{array}{r}-0.11 \\
(3017)\end{array}$ & $\begin{array}{r}-0.06 \\
(3017)\end{array}$ & $\begin{array}{r}-0.10 \\
(3017)\end{array}$ & $\begin{array}{r}-0.03 \\
(3017)\end{array}$ & $\begin{array}{r}0.07 \\
(3017)\end{array}$ & $\begin{array}{r}-0.01 \\
(3017)\end{array}$ & $\begin{array}{r}-0.09 \\
(3017)\end{array}$ & & \\
\hline $\begin{array}{l}\text { Populaion } \\
\text { density }\end{array}$ & $\begin{array}{r}0.25 \\
(876)\end{array}$ & $\begin{array}{l}-0.12 \\
(876)\end{array}$ & $\begin{array}{r}0.16 \\
(876)\end{array}$ & $\begin{array}{r}0.05 \\
(876)\end{array}$ & $\begin{array}{l}-0.19 \\
(876)\end{array}$ & $\begin{array}{l}-0.03 \\
(876)\end{array}$ & $\begin{array}{l}-0.13 \\
(876)\end{array}$ & $\begin{array}{l}-0.76 \\
(868)\end{array}$ & \\
\hline $\begin{array}{l}\text { Weaning } \\
\text { age }\end{array}$ & $\begin{array}{r}-0.15 \\
(1023)\end{array}$ & $\begin{array}{r}0.03 \\
(1023)\end{array}$ & $\begin{array}{r}-0.14 \\
(1023)\end{array}$ & $\begin{array}{r}-0.03 \\
(1023)\end{array}$ & $\begin{array}{r}0.15 \\
(1023)\end{array}$ & $\begin{array}{r}-0.03 \\
(1023)\end{array}$ & $\begin{array}{r}-0.11 \\
(1023)\end{array}$ & $\begin{array}{r}0.60 \\
(1006)\end{array}$ & $\begin{array}{l}-0.57 \\
(545)\end{array}$ \\
\hline
\end{tabular}




\title{
Appendix S2. Species-based models: complementary results
}

\author{
Intrinsic predictors of vulnerability
}

Table S8. Results of the intrinsic PGLS including all mammals with available data. Model II is presented in the main manuscript. Models II, I3 and I4 exclude species classified as threatened following criterion B.

Model I2 includes all species with available data for the presented variables. Model I4 includes all terrestrial mammals in the IUCN Red List after imputation of data for missing traits. $\beta$, coefficient estimates; $S E$, standard errors of the coefficients.

\begin{tabular}{|c|c|c|c|c|}
\hline \multirow{2}{*}{ Traits } & Model I1 (N=981) & Model I2 (N=1027) & Model I3 (N=2747) & Model I4 (N=3595) \\
\hline & $\beta(\mathrm{SE})$ & $\beta(\mathrm{SE})$ & $\beta(\mathrm{SE})$ & $\beta(\mathrm{SE})$ \\
\hline Geographic range & $-0.45(0.028) * * *$ & - & $-0.44(0.015)^{* * *}$ & $\begin{array}{l}-0.42 \\
(0.014)^{* * *}\end{array}$ \\
\hline Weaning age & $0.26(0.127)^{*}$ & $0.31(0.147)^{*}$ & - & $\begin{array}{l}-0.27 \\
(0.066) * * *\end{array}$ \\
\hline Body mass & $0.29(0.047)^{* * *}$ & $0.28(0.052)^{* * *}$ & $0.31(0.031)^{* * *}$ & $\begin{array}{l}0.28 \\
(0.033) * * *\end{array}$ \\
\hline Adjusted $\mathrm{R}^{2}$ & 0.25 & 0.06 & 0.25 & 0.22 \\
\hline
\end{tabular}

\section{Note about the imputation technique}

The results thrown by model I4 (Table S8) show that weaning age negatively relate to threat status, i.e. terrestrial mammals with a later maturation are less likely to be threatened. This contradicts previous studies and is biologically unlikely (e.g. Davidson et al. 2009; Marco et al. 2014). Imputed data to fit model I4 were obtained based on the available $\log _{10}$-transformed data for geographic range (sq. $\mathrm{km}$ ), weaning age (days) and body mass ( $\mathrm{g}$ ) and the supertree of Bininda-Emonds et al. (2007) presented by Fritz et al. (2009); using the phylopars and phylopars.predicts functions from the 'Rphylopars' package (Goolsby et al., 2015) in R (R Core Team, 2014).

To further understand these results, we additionally followed the same procedure but using a more complete database including the three mentioned traits plus population density (excluded from the analyses due to its correlation with body mass). Results from these two different imputation processes are quite different (Fig. S2), especially for those variables with less available data like weaning age (Fig. S2c). This suggests that imputed values are highly dependent on the initial subset of variables from which the function imputes data and call for caution when interpreting results. 

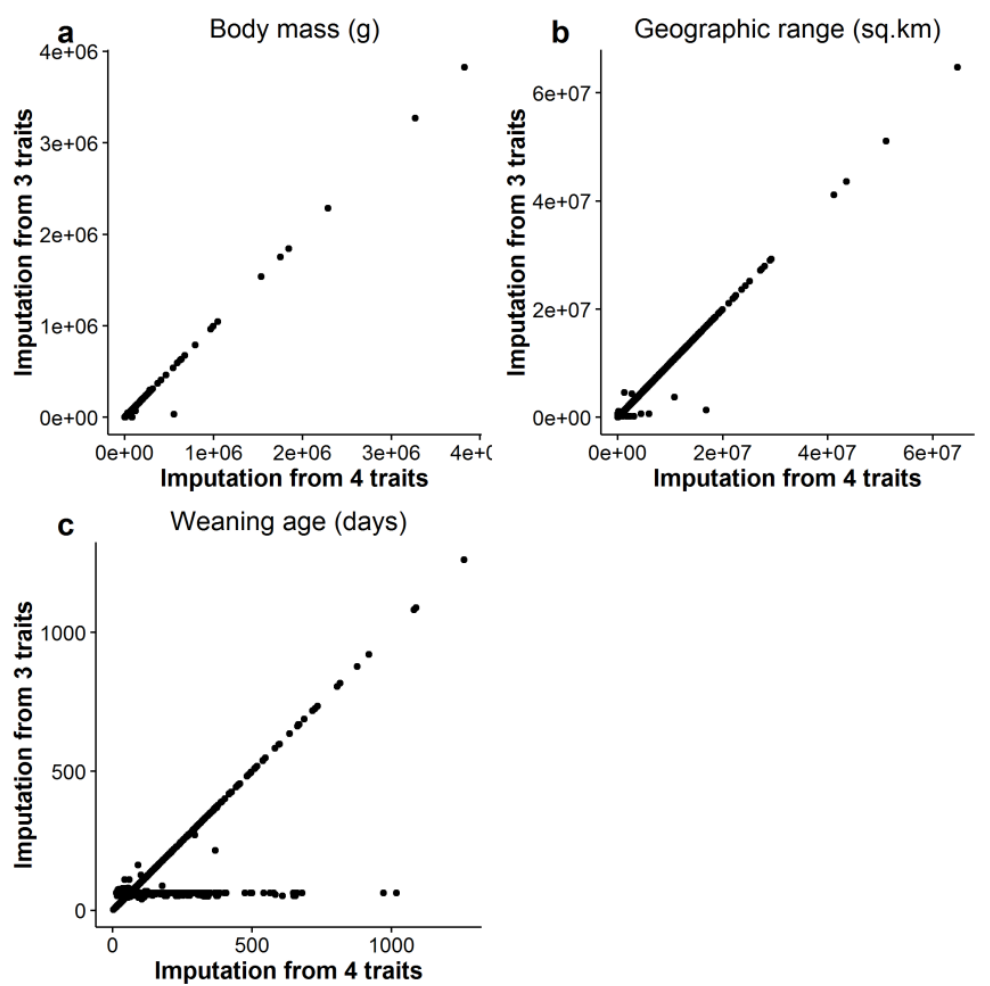

Figure S2. Linear regression between the imputed values of the three intrinsic predictors of vulnerability, based on 4 traits in the original data set (X-axis) and based on 3 traits in the original data set ( $\mathrm{Y}$-axis).

\section{Anthropogenic predictors of vulnerability}

Table S9. Results of the anthropogenic PGLS for all mammals. Model Al is included in the main manuscript, including all mammals with available distribution data and phylogenetic information. Model A2 includes the same species as the main model fitted for intrinsic traits (Model I1, Table S8), except from four species which geographic range did not overlap with the Anthromes geographic data (Table S5). $\beta$, coefficient estimates; $S E$, standard errors of the coefficients.

\begin{tabular}{lll}
\hline \multirow{2}{*}{ Anthromes } & Model A1 $(\mathrm{N}=3908)$ & Model A2 $(\mathrm{N}=977)$ \\
\cline { 2 - 3 } & $\beta(\mathrm{SE})$ & $\beta(\mathrm{SE})$ \\
\hline Villages & $0.00(0.01)$ & $-0.01(0.015)$ \\
Croplands & $0.08(0.012)^{* * *}$ & $0.09(0.027)^{* * *}$ \\
Rangelands & $0.00(0.009)$ & $-0.02(0.019)$ \\
Semi-natural & $0.22(0.012)^{* * *}$ & $0.20(0.029)^{* * *}$ \\
Wildlands & $-0.17(0.009)^{* * *}$ & $-0.13(0.021)^{* * *}$ \\
\hline Adjusted $\mathrm{R}^{2}$ & 0.13 & 0.07 \\
\hline$* * * \mathrm{p}<0.001 ; * * \mathrm{p}<0.01 ; * \mathrm{p}<0.05$ &
\end{tabular}


Intrinsic and anthropogenic predictors of vulnerability

Table S10. Results of the PGLS including both intrinsic and anthropogenic variables for all mammals. $\beta$, coefficient estimates; $S E$, standard errors of the coefficients. $(\mathrm{N}=955)$

\begin{tabular}{ll}
\hline Traits & $\beta(\mathrm{SE})$ \\
\hline Geographic range & $-0.43(0.034)^{* * *}$ \\
Weaning age & $0.25(0.126)^{*}$ \\
Body mass & $0.25(0.048)^{* * *}$ \\
Villages & $0.02(0.014)$ \\
Croplands & $0.09(0.024)^{* * *}$ \\
Rangelands & $-0.04(0.017)^{*}$ \\
Semi-natural & $0.05(0.029)$ \\
Wildlands & $-0.03(0.021)$ \\
\hline Adjusted $\mathrm{R}^{2}$ & 0.25 \\
\hline$* * * \mathrm{p}<0.001 ; * * \mathrm{p}<0.01 ; * \mathrm{p}<0.05$ &
\end{tabular}




\section{Appendix S3. Spatial predictions: data \& results}

The gridded distribution of mammals was obtained by overlapping a $1 \times 1^{\circ}$ grid with every species geographic range in ArcView 3.2. (ESRI, 1999). Grids were projected in Eckert IV (equal area) to match the projection of the land use original data source (see below). Therefore, not all grids have the same area, ranging from 1402 $\mathrm{km}^{2}$ (in the Poles) to $12391 \mathrm{~km}^{2}$ (in the Equator). These differences in grid-cell size should not be a problem, since the only purpose of gridding the study area is to spatially represent predictions based on adjusted coefficients of previous fitted models at the species level.

The nomenclature employed in this section follows the models on previous appendices.

\section{Intrinsic vulnerability}

As this is not a spatial parameter per se, different paths to estimate intrinsic vulnerability and map it can be followed. Previous studies have used the average prediction (based on life-history and ecological traits) for all species occurring within a certain grid cell (Cardillo et al., 2006), but this approach limits the analyses to species with data on all traits included in the model. Therefore, we explored an additional approach based on calculating the median value for all traits included in the model -aiming to represent the "average" mammal occurring within each grid cell- and predicted based on these values. This approach may produce combinations of traits that are not biologically realistic (e.g. late weaning age and small body size) but allows us to include information from as many species as possible. We also explore an approach based on average predictions and below we compare from both approaches.

On the first place, we predicted intrinsic vulnerability based on the median trait values per grid using the four versions of the intrinsic model. All the alternatives are displayed in figs. S2a, S2d, S2g and S2j (first column); with each row representing a different model from Table S2 (Models I1, I2, I3 and I4, respectively). These predictions show qualitatively the same, well-correlated results (Spearman's $\rho, 0.72-0.99$ ) with a moderate level of spatial coincidence among areas of high vulnerability (50\% of areas are classified as such independently of the model employed) and low vulnerability (51\% of areas are classified as such independently of the model employed). Non-coincident areas were very rarely classified as the opposite (i.e. high vulnerability as low vulnerability areas or vice versa); they normally were considered as non-significant. Areas of high and low vulnerability were defined based on spatial autocorrelation clusters, calculated as local Moran's I values within queen neighbors grid-cells (positive significant correlation, $\mathrm{p}<0.01$ ).

Secondly, we defined spatial intrinsic vulnerability (per grid cell) as the mean value of the predicted value for species occupying that area. The results from this approach are shown in figures S2b, S2e, S2h and S2k 
(second column). Differences among rows represent the various models used for prediction (Models I1, I2, I3 and $I 4$, respectively) that have relatively high correlation (Spearman's $\rho, 0.54-0.85$ ) and moderate coincidence among areas of high vulnerability (49\% of areas are classified as such independently of the model employed) and low vulnerability ( $44 \%$ of areas are classified as such independently of the model employed).

Both approaches (prediction from median trait values and mean of species predictions) provide similar results (Table S11), but as presented above, we found more differences among alternative models when averaging species predictions by grid cell than when using median values per grid cell. Thus, we focused on the approach based on median traits per grid cell and including more predictors in the main manuscript.

Table S11. Correlations between intrinsic vulnerability predictions based on the same model, but using different calculations for their spatial representation (prediction from median trait values and mean of species predictions; first vs. second column in Fig. S2). Spearman's $\rho$ values are provided.

\begin{tabular}{ll}
\hline Species-based model & Spearman's $\rho$ between predictions \\
\hline I1 & 0.77 \\
I2 & 0.81 \\
I3 & 0.91 \\
I4 & 0.91 \\
\hline
\end{tabular}




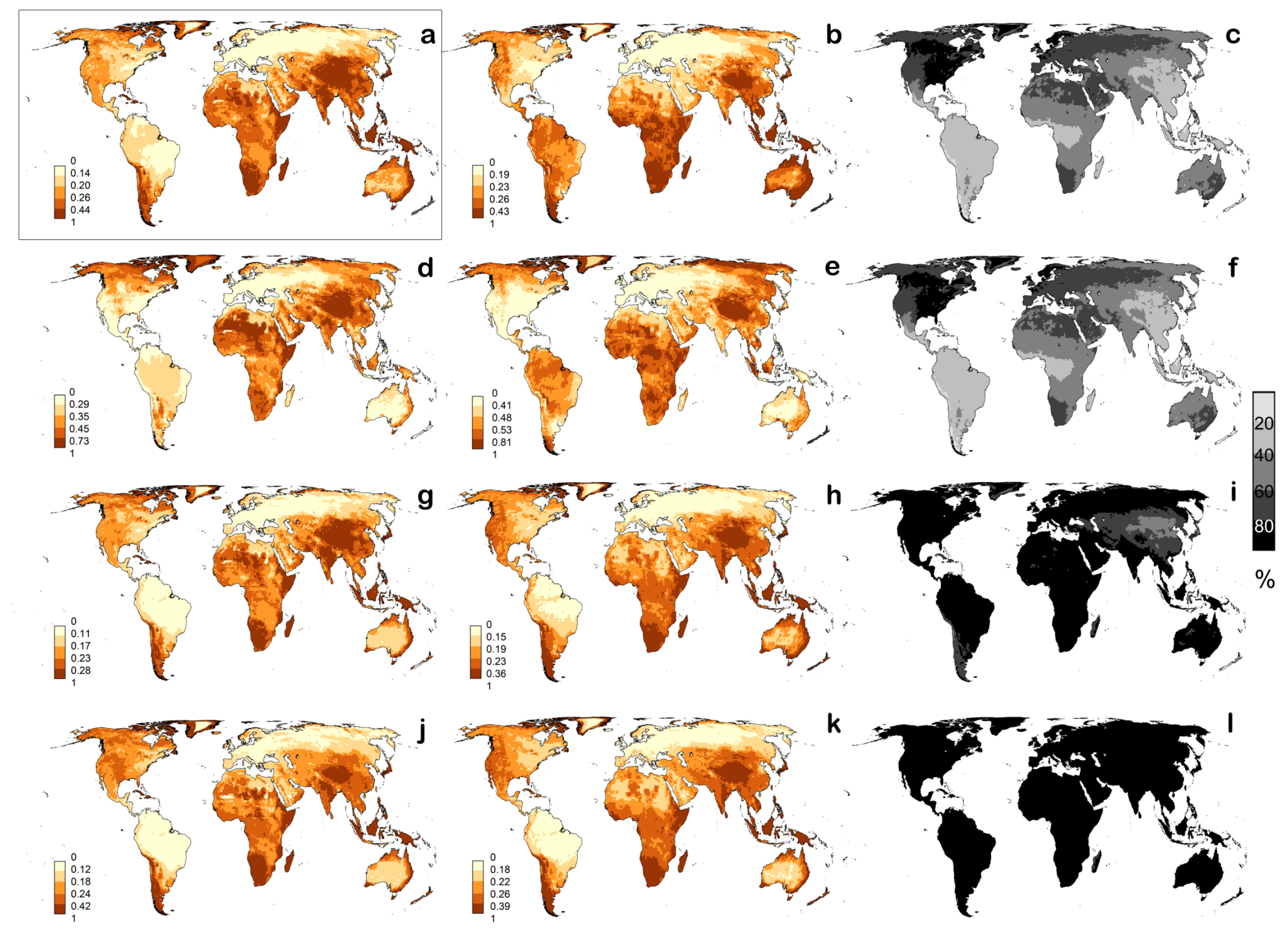


Figure S3. Spatial intrinsic vulnerability calculated as the prediction from the median terrestrial mammal inhabiting each grid cell (a, $d$, g \& $j$ ), and as the mean value of vulnerability per species occurring within a grid cell (b, e, h \& k). First-row predictions (a \& b) are based on Model Il (main manuscript), including geographic range, adult body mass and weaning age. Second row ( $\mathrm{d}$ e) shows predictions from Model I2, combining adult body mass and weaning age. Third-row maps ( $\mathrm{g} \& \mathrm{~h}$ ) are predicted using Model I3: adult body mass and geographic range. Last-row predictions are based on the model with imputed data (Model I4), including the three traits (Table S7). Percentage of available data (number of species for which data included in the models were available, over the total mammals known to be present in each grid cell) are presented in the last column (c, f, i \& 1), to show the uncertainty when mapping vulnerability in this way. All predictions (of continuous Red List Status) are standardized between 0-1 to facilitate comparison, and divided by data quantiles, with darker colors indicating higher vulnerability. Map of data availability presents equal breaks, as indicated on the legend. Framed map shows the version included in the main text. 


\section{Extrinsic vulnerability}

Species-based models were adjusted based on two different subgroups of terrestrial mammals, one including all species with available information ( $\mathrm{Model} \mathrm{Al}$ ) and the other including only species included in the intrinsic species-based model (Model A2). Spatial predictions on Figs. S3a and S3b correspond to Model A1, whereas predictions of Figs. S3c and S3d are based on Model A2. Differences between maps on the left (S3a and S3c) and right columns (S3b and S3d) are consequence of the method used to define extrinsic vulnerability at the grid-cell level. In the first case, grid cells are considered "new species" for which percentage of land covered by the different anthromes per grid cell are the new explanatory variables. In the second case, extrinsic vulnerability is calculated as the mean extrinsic vulnerability, predicted for all species occurring within a grid cell (for comparison with the approach explored for intrinsic traits).

There is high coincidence between Model A1 (S3a) and Model A2 (S3c), with a Spearman's rank correlation coefficient $(\rho)$ of 0.97 . Areas of high extrinsic vulnerability (calculated as univariate local Moran's I) coincide in $83 \%$ of cases, and low extrinsic vulnerability is assigned equally with both models in $84 \%$ of cases. Results are thus, not very sensitive to differences in the subset of species included in model A1 versus A2.

In the case of predictions made by averaging the individual extrinsic vulnerabilities of all species inhabiting each grid cell, results from the model including all species and the one including only those with intrinsic information available (S3b vs. S3d) are not that similar, despite a high Spearman's rank correlation value $(\rho=$ 0.94). Areas of high extrinsic vulnerability coincide in $76 \%$ of cases, while low vulnerability clusters only coincide in $33 \%$ of cases. Areas of high vulnerability are relatively persistent, whereas many low intrinsic vulnerability areas disappear when considering only a subset of species (Fig. S3d).

In general, differences among methods to spatially represent extrinsic vulnerability are not large (Table S12). However, areas of high and low vulnerability substantially vary depending on the employed method to spatially predict. Hence, it is not trivial to choose one approach or the other. In our case, we believe predicting based on the actual cover is more informative and allows to pick more restricted areas, without the limitation of the "buffer effect" (consequence of the nature of species' geographic ranges) that appears in cases b and d (Fig. 3S).

Table S12. Correlations between extrinsic vulnerability predictions based on the same model, but using different calculations for spatial representation (prediction from median trait values and mean of species predictions; first vs. second column in Fig. S3). Spearman's $\rho$ values are provided. 


\begin{tabular}{ll}
\hline Species-based model & Spearman's $\rho$ between predictions \\
\hline A1 & 0.60 \\
A2 & 0.60 \\
\hline
\end{tabular}
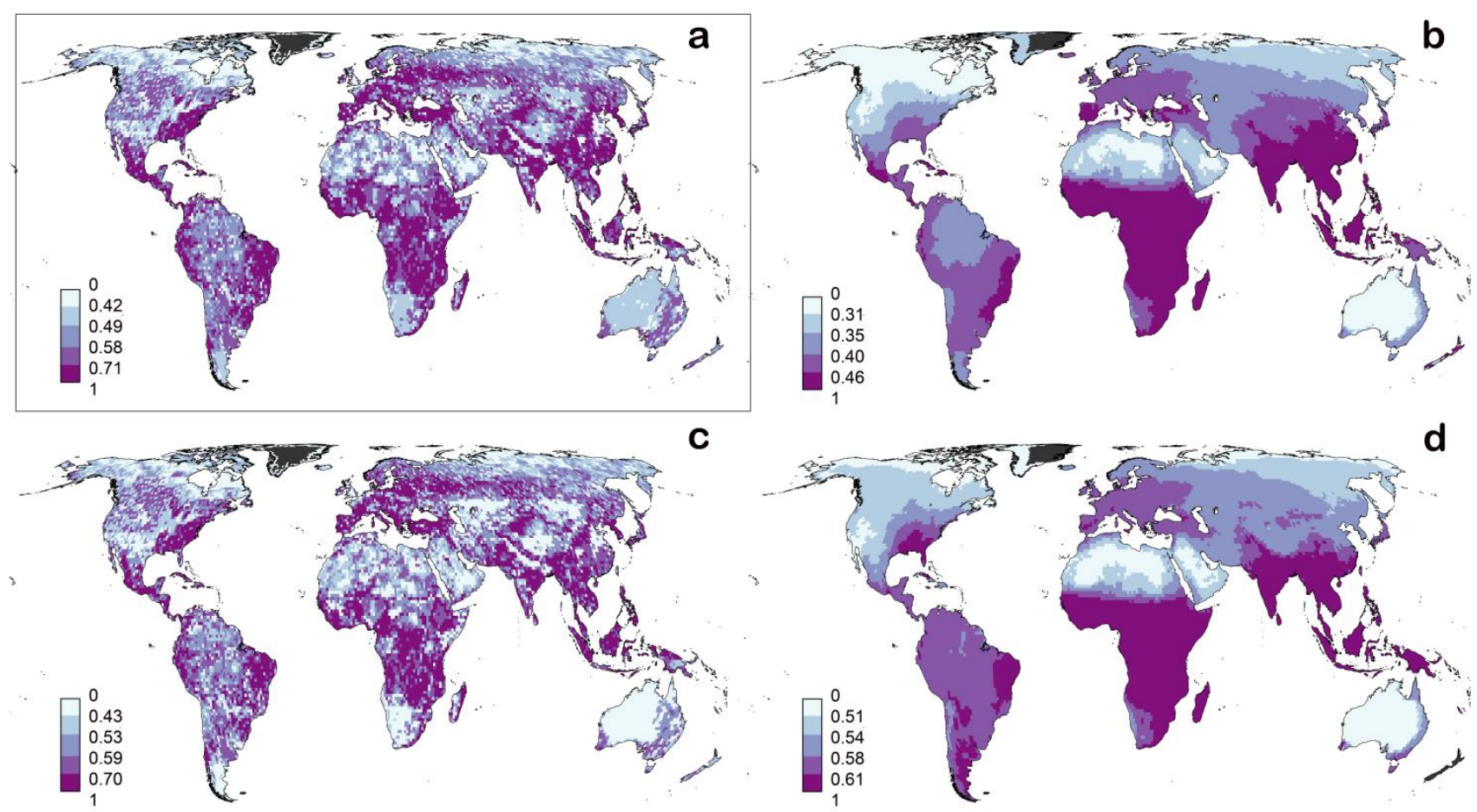

Figure S4. Spatial extrinsic vulnerability calculated as the prediction from the proportion of anthromes occurring within each grid cell (a \& c), and as the mean value of vulnerability per species occurring within a grid cell (b \& d). First-row predictions (a \& b) are based on Model Al (main manuscript), and the alternative including the same species as the main intrinsic model (c \& d; Model A2; Table S8). All predictions (of continuous Red List Status) are standardized between 0-1 to facilitate comparison; legend's categories follow quantiles' division. Darker colors indicate higher vulnerability. Black areas indicate no data. Framed map shows the version included in the main text. 


\section{Zonation}

Zonation is based on areas where high values of high/low intrinsic and extrinsic vulnerability coexist (positive spatial autocorrelation) or counteract (negative spatial autocorrelation) each other. In the main manuscript we presented the map of zones based on all terrestrial mammals, and also two separate zonations for small $(\leq 3 \mathrm{~kg})$ and large mammals (>3 kg). As expected, the delimination of these areas varies depending on the subset of species analyzed.

Tables S13 to S15 present a description of the main characteristics of the identified zones including species' trait data availability, mammalian richness, and number of threatened mammals. In addition, we have included descriptive maps to illustrate the predominant anthromes' classes within each of the zone categories based on all mammals (Fig. S5), only small (Fig. S6) and only large mammals (Fig. S7). 
Table S13. Summary of the available information for the traits employed to calculate intrinsic vulnerability, and numbers of threatened and total mammalian richness, global and segregated by zone category. Calculations are based on all terrestrial mammal species ( $\mathrm{N}=5237)$. Mean refers to the mean number of mammals with available information by grid cell, \% is that number divided by the total mammalian richness by grid cell; Min-max shows the minimum and maximum number of mammals with information by grid cell. $N$ indicates the number of grid cells included in that zone.

\begin{tabular}{|c|c|c|c|c|c|c|c|c|c|c|c|c|c|c|c|}
\hline \multirow[t]{2}{*}{ Variable } & \multicolumn{3}{|c|}{ Global (N=17474) } & \multicolumn{3}{|c|}{ Double-susceptibility $(\mathrm{N}=2068)$} & \multicolumn{3}{|c|}{ Intrinsic-susceptibility $(\mathrm{N}=2370)$} & \multicolumn{3}{|c|}{ Extrinsic-susceptiblity $(\mathrm{N}=2945)$} & \multicolumn{3}{|c|}{ Low-susceptibility $(\mathrm{N}=2530)$} \\
\hline & Mean & $\% \mathrm{r}$ & Min-max & Mean & $\% \mathrm{r}$ & Min-max & Mean & $\% \mathrm{r}$ & Min-max & Mean & $\% \mathrm{r}$ & Min-max & Mean & $\% \mathrm{r}$ & Min-max \\
\hline \multicolumn{16}{|l|}{ Species knowledge } \\
\hline geographic range & 55.7 & $100 \%$ & $1-252$ & 86.4 & $100 \%$ & $1-252$ & 22.0 & $100 \%$ & $1-141$ & 84.5 & $100 \%$ & $1-241$ & 48.2 & $100 \%$ & $1-233$ \\
\hline body mass & 48.4 & $87 \%$ & $1-213$ & 71.9 & $83 \%$ & $1-213$ & 19.3 & $88 \%$ & $1-114$ & 74.6 & $88 \%$ & $1-211$ & 43.4 & $90 \%$ & $1-203$ \\
\hline weaning age & 27.9 & $50 \%$ & $1-104$ & 35.0 & $41 \%$ & $1-103$ & 13.9 & $63 \%$ & $1-70$ & 39.7 & $47 \%$ & $1-101$ & 25.0 & $52 \%$ & $1-66$ \\
\hline Threatened species & 2.6 & $5 \%$ & $0-40$ & 6.7 & $8 \%$ & $0-38$ & 1.6 & $7 \%$ & $0-25$ & 2.8 & $3 \%$ & $0-20$ & 1.3 & $3 \%$ & $0-16$ \\
\hline Data deficient species & 1.3 & $2 \%$ & $0-20$ & 2.3 & $3 \%$ & $0-20$ & 0.2 & $1 \%$ & $0-9$ & 2.7 & $3 \%$ & $0-20$ & 1.1 & $2 \%$ & $0-16$ \\
\hline Richness & 55.7 & - & $1-252$ & 86.4 & - & $1-252$ & 22.0 & - & $1-141$ & 84.5 & - & $1-241$ & 48.2 & - & $1-233$ \\
\hline
\end{tabular}

${ }^{\# 1} 100 \%$ availability is inherent to the nature of the analysis. If there is not information about geographic range, the species cannot enter the model.

Table S14. Summary of the available information of the selected traits employed to calculate intrinsic vulnerability, and numbers of threatened and total mammalian richness, global and segregated by zone category. Calculations are based on species smaller or equal than $3 \mathrm{~kg}$ (N=2773). Mean refers to the mean number of mammals with available information by grid; \% is that number divided by the total mammalian richness by grid cell; range shows the minimum and maximum number of mammals with information by grid cell. $N$ indicates the number of grid cells included in that zone.

\begin{tabular}{|c|c|c|c|c|c|c|c|c|c|c|c|c|c|c|c|}
\hline \multirow[t]{2}{*}{ Variable } & \multicolumn{3}{|c|}{ Global (N=16699) } & \multicolumn{3}{|c|}{ Double-susceptibility $(\mathrm{N}=3165)$} & \multicolumn{3}{|c|}{ Intrinsic-susceptibility $(\mathrm{N}=651)$} & \multicolumn{3}{|c|}{ Extrinsic-susceptiblity $(\mathrm{N}=1768)$} & \multicolumn{3}{|c|}{ Low-susceptibility (4808) } \\
\hline & Mean & $\% \mathrm{r}$ & Min-max & Mean & $\% \mathrm{r}$ & Min-max & Mean & $\% \mathrm{r}$ & Min-max & Mean & $\% \mathrm{r}$ & Min-max & Mean & $\% \mathrm{r}$ & Min-max \\
\hline \multicolumn{16}{|l|}{ Species knowledge } \\
\hline geographic range & 36.3 & $100 \%$ & $1-178$ & 50.7 & $100 \%$ & $1-178$ & 28.1 & $100 \%$ & $1-138$ & 44.8 & $100 \%$ & $1-142$ & 16.6 & $100 \%$ & $1-138$ \\
\hline body mass & 36.3 & $100 \%$ & $1-178$ & 50.7 & $100 \%$ & $1-178$ & 28.1 & $100 \%$ & $1-138$ & 44.8 & $100 \%$ & $1-142$ & 16.6 & $100 \%$ & $1-138$ \\
\hline weaning age & 17.5 & $48 \%$ & $1-58$ & 20.4 & $40 \%$ & $1-58$ & 10.5 & $38 \%$ & $1-54$ & 23.1 & $52 \%$ & $1-45$ & 10.9 & $66 \%$ & $1-37$ \\
\hline Threatened species & 0.6 & $2 \%$ & $0-21$ & 1.1 & $2 \%$ & $0-17$ & 1.4 & $5 \%$ & $0-21$ & 0.6 & $1 \%$ & $0-6$ & 0.0 & $0 \%$ & $0-2$ \\
\hline Data deficient species & 0.6 & $2 \%$ & $0-12$ & 1.0 & $2 \%$ & $0-12$ & 0.9 & $3 \%$ & $0-12$ & 0.9 & $2 \%$ & $0-9$ & 0.0 & $0 \%$ & $0-6$ \\
\hline
\end{tabular}


Table S15. Summary of the available information of the selected traits employed to calculate intrinsic vulnerability and numbers of threatened, and total mammalian richness, global and segregated by zone category. Calculations are based on species larger than $3 \mathrm{~kg}(\mathrm{~N}=538)$. Mean refers to the mean number of mammals with available information by grid; $\%$ is that number divided by the total mammalian richness by grid cell; range shows the minimum and maximum number of mammals with information by grid cell. $N$ indicates the number of grid cells included in that zone.

\begin{tabular}{|c|c|c|c|c|c|c|c|c|c|c|c|c|c|c|c|}
\hline \multirow[t]{2}{*}{ Variable } & \multicolumn{3}{|c|}{ Global (N=17183) } & \multicolumn{3}{|c|}{ Double-susceptibility $(\mathrm{N}=1817)$} & \multicolumn{3}{|c|}{ Intrinsic-susceptibility $(\mathrm{N}=1796)$} & \multicolumn{3}{|c|}{ Extrinsic-susceptiblity $(\mathrm{N}=2614)$} & \multicolumn{3}{|c|}{ Low-susceptibility $(\mathrm{N}=2394)$} \\
\hline & Mean & $\% \mathrm{r}$ & Min-max & Mean & $\% \mathrm{r}$ & Min-max & Mean & $\% \mathrm{r}$ & Min-max & Mean & $\% \mathrm{r}$ & Min-max & Mean & $\% \mathrm{r}$ & Min-max \\
\hline \multicolumn{16}{|l|}{ Species knowledge } \\
\hline geographic range & 13.4 & $100 \%$ & $1-60$ & 21.5 & $100 \%$ & $1-59$ & 9.6 & $100 \%$ & $1-53$ & 12.0 & $100 \%$ & $1-37$ & 9.3 & $100 \%$ & $1-31$ \\
\hline body mass & 13.4 & $100 \%$ & $1-60$ & 21.5 & $100 \%$ & $1-59$ & 9.6 & $100 \%$ & $1-53$ & 12.0 & $100 \%$ & $1-37$ & 9.3 & $100 \%$ & $1-31$ \\
\hline weaning age & 10.8 & $81 \%$ & $1-48$ & 15.0 & $70 \%$ & $1-46$ & 8.1 & $84 \%$ & $1-41$ & 9.8 & $81 \%$ & $1-26$ & 8.1 & $87 \%$ & $1-24$ \\
\hline Threatened species & 1.9 & $14 \%$ & $0-49$ & 6.2 & $29 \%$ & $0-49$ & 1.3 & $14 \%$ & $0-38$ & 1.2 & $81 \%$ & $0-13$ & 0.9 & $9 \%$ & $0-6$ \\
\hline Data deficient species & 0.1 & $1 \%$ & $0-3$ & 0.1 & $0 \%$ & $0-2$ & 0.0 & $0 \%$ & $0-2$ & 0.3 & $10 \%$ & $0-3$ & 0.1 & $1 \%$ & $0-3$ \\
\hline Richness & 13.4 & - & $1-60$ & 21.5 & - & $1-59$ & 9.6 & - & $1-53$ & 12.0 & - & $1-37$ & 9.3 & - & $1-31$ \\
\hline
\end{tabular}

${ }^{\#} 100 \%$ availability is inherent to the nature of the analysis. If there is not information about geographic range, the species cannot enter the model. 

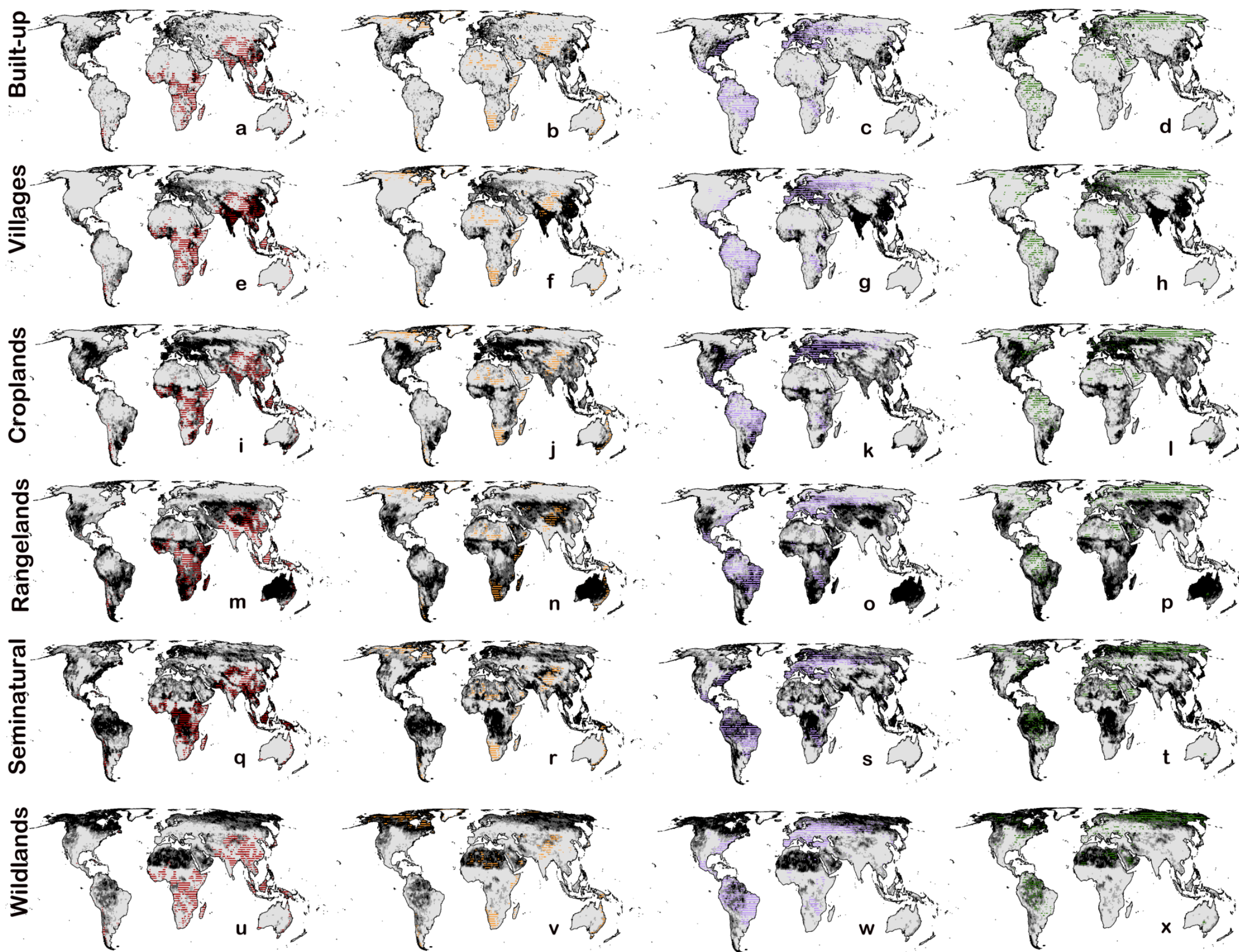
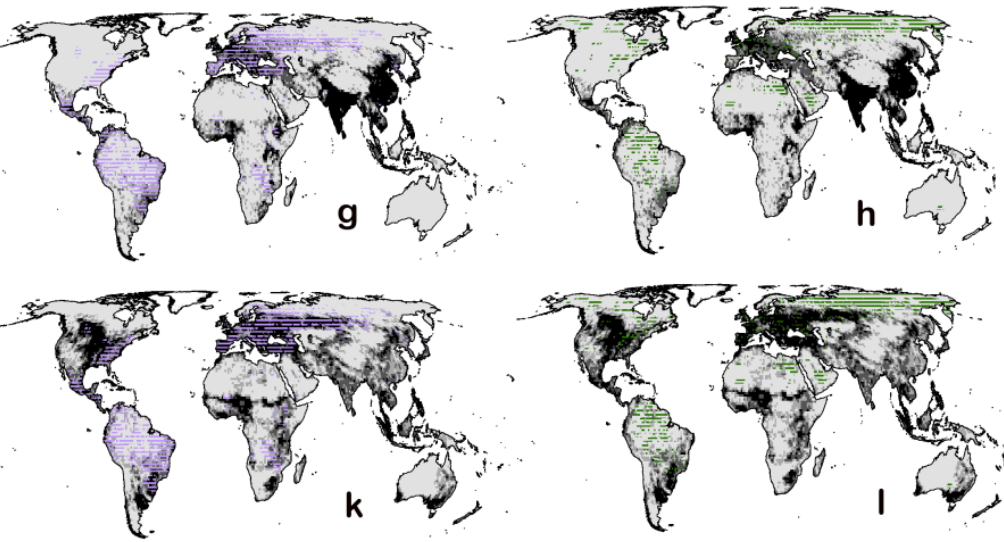

Figure S5. Representation of the percentage per grid-cell covered by each of the six anthromes' categories (built-up areas,

villages, croplands, rangelands, seminatural lands and wildlands), one in each row. Darker filling represents higher coverage of a certain anthrome. One zone category is overlapped in each column: double-susceptibility areas (panels a, e, i, m, q and u; red), intrinsic- susceptibility areas (panels b, f, j, n, r and v; orange), extrinsic-susceptibility areas (panels c, g, k, o, s and w; purple) and negligible-

susceptibility areas (panels d, h, l, $\mathrm{p}, \mathrm{t}$ and $\mathrm{x}$; green). Zonation based on all terrestrial mammals.
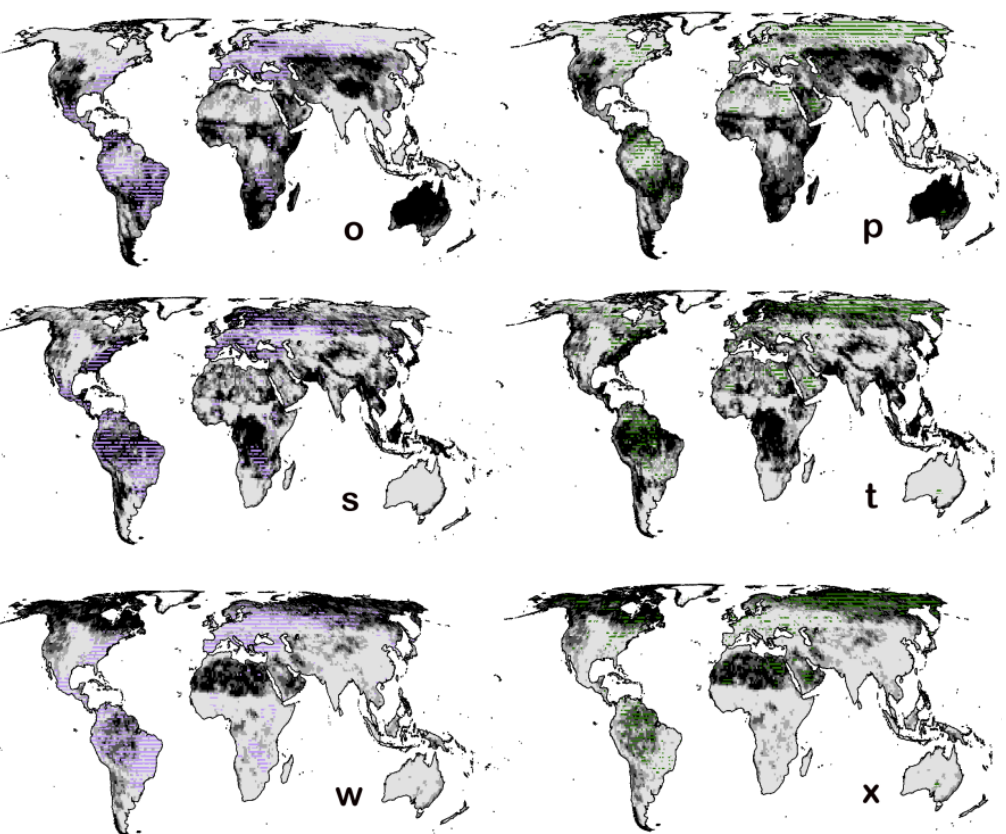

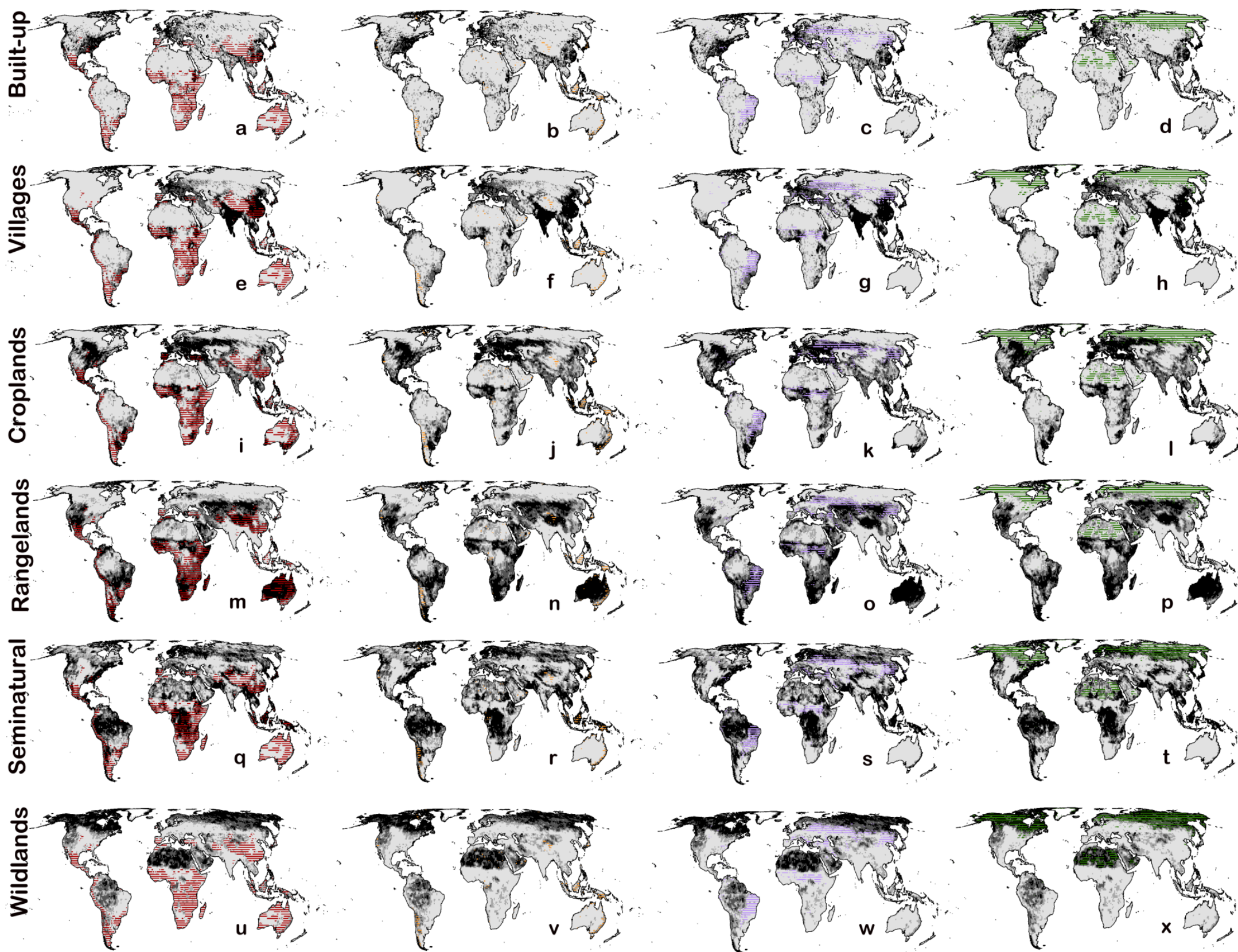
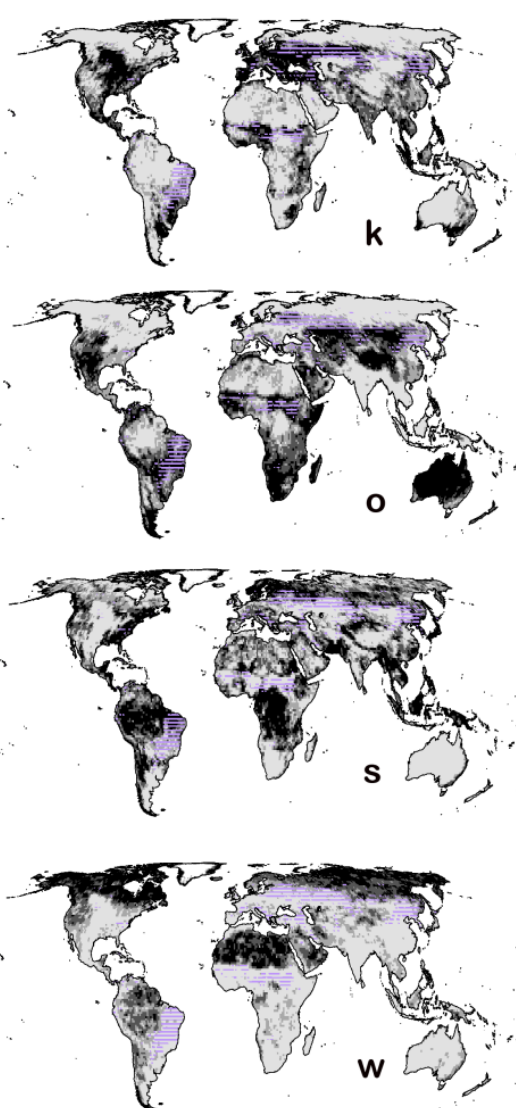

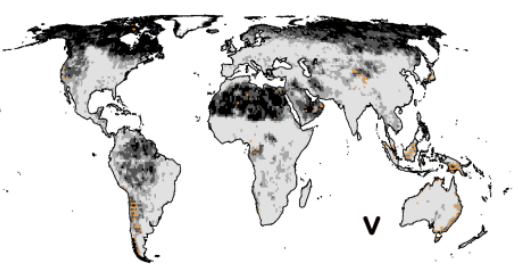

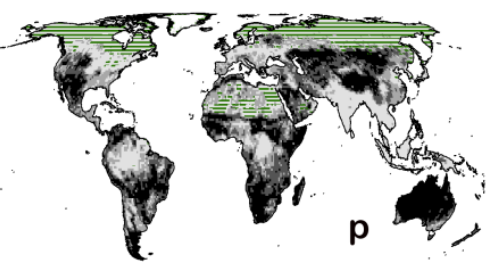
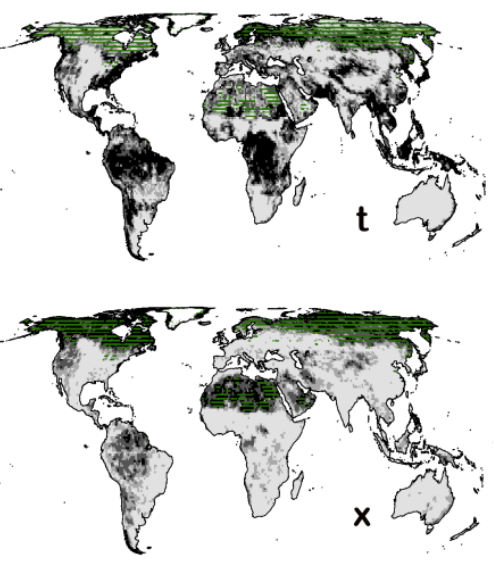

Figure S6. Representation of the percentage per grid-cell covered by each of the six anthromes'

categories (built-up areas,

villages, croplands, rangelands,

seminatural lands and wildlands), one in each row. Darker filling represents higher coverage of a certain anthrome. One zone

category is overlapped in each column: double-susceptibility areas (panels a, e, i, m, q and u; red), intrinsic- susceptibility areas (panels b, f, j, n, $r$ and $v$; orange), extrinsic-susceptibility areas (panels c, g, k, o, s and w; purple) and negligible-

susceptibility areas (panels d, h, 1, $\mathrm{p}, \mathrm{t}$ and $\mathrm{x}$; green). Zonation based on terrestrial mammals smaller/equal than $3 \mathrm{~kg}$. 

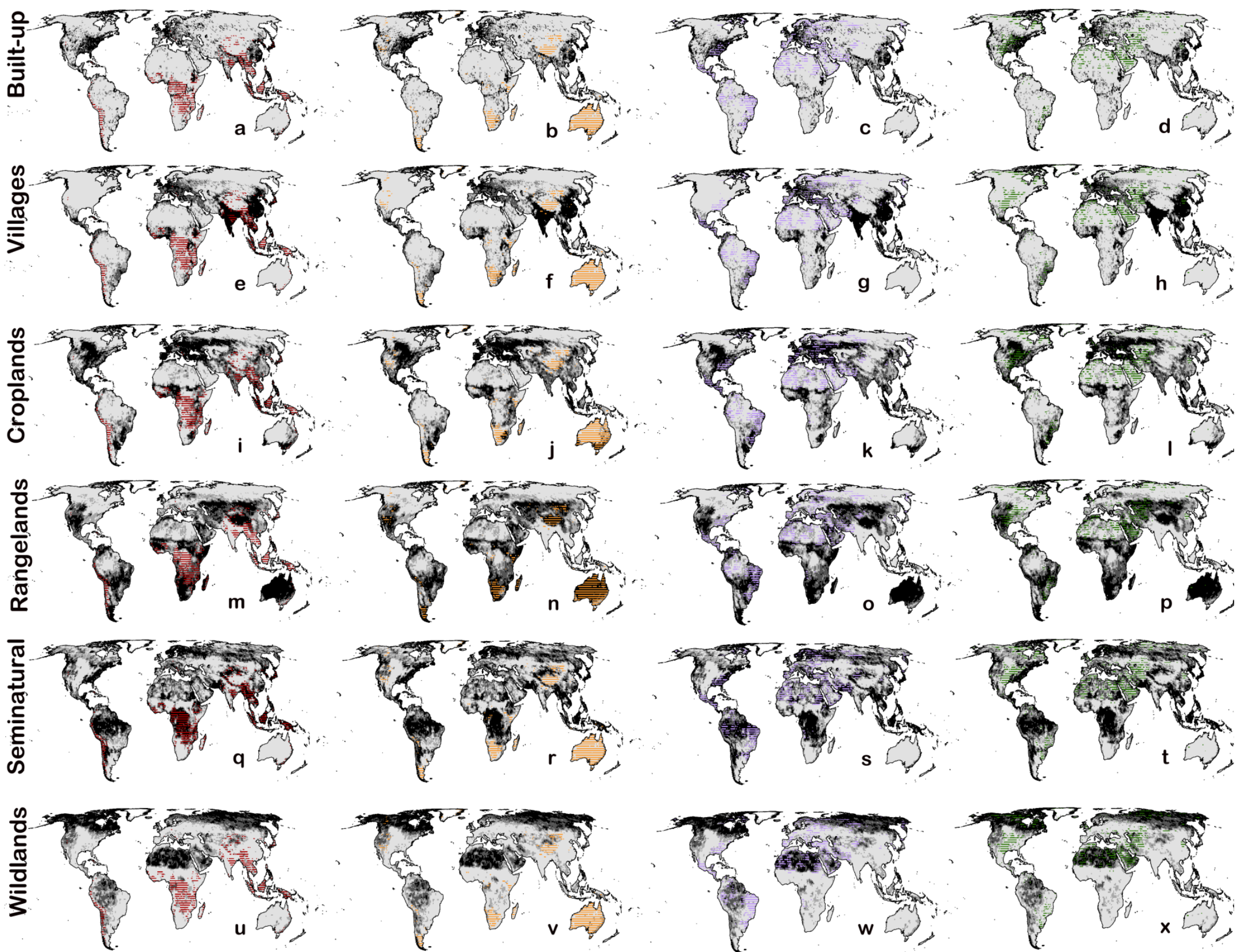
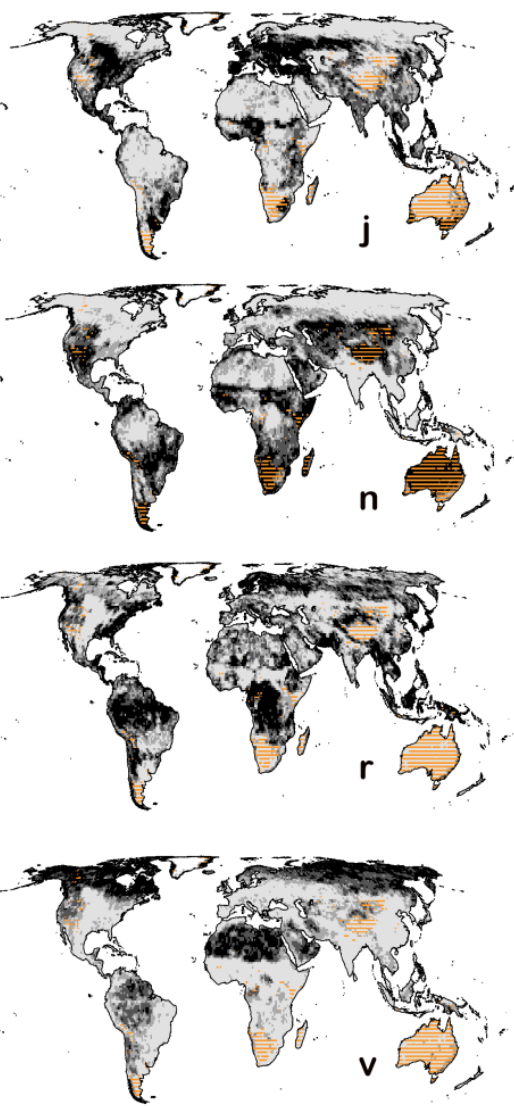

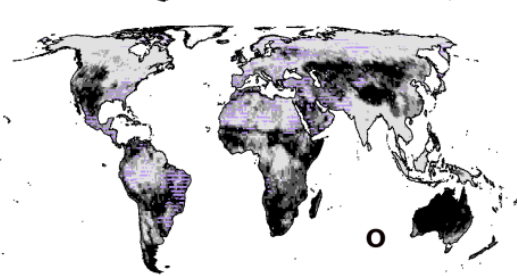

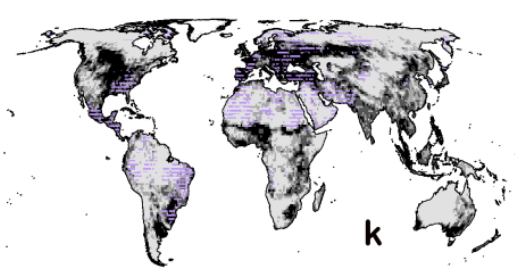
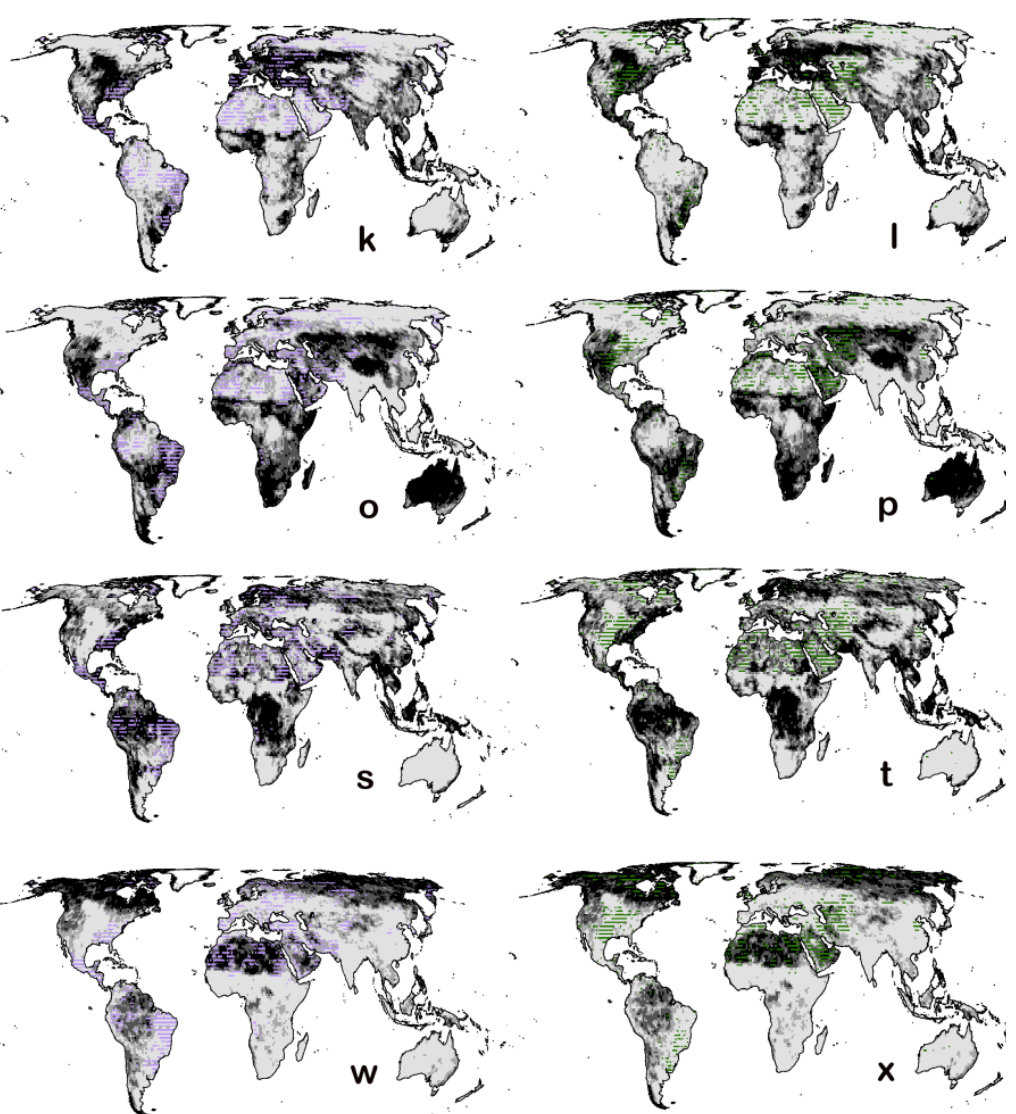

Figure S7. Representation of the percentage per grid-cell covered by each of the six anthromes

cailt-up areas,

villages, croplands, rangelands, seminatural lands and wildlands) one in each row. Darker filling represents higher coverage of a certain anthrome. One zone category is overlapped in each column: double-susceptibility areas (panels a, e, i, m, q and u; red), intrinsic- susceptibility areas (panels b, f, j, n, r and v; orange), extrinsic-susceptibility areas (panels c, g, k, o, s and w; purple) and negligible-

susceptibility areas (panels d, h, 1 ,

$\mathrm{p}, \mathrm{t}$ and $\mathrm{x}$; green). Zonation based on terrestrial mammals larger than $3 \mathrm{~kg}$. 


\section{References}

Bininda-Emonds O.R.P., Cardillo M., Jones K.E., Macphee R.D.E., Beck R.M.D., Grenyer R., Price S.A., Vos R.A., Gittleman J.L., \& Purvis A. (2007) The delayed rise of present-day mammals. Nature, 446, 507-512.

Cardillo M., Mace G.M., Gittleman J.L., Jones K.E., Bielby J., \& Purvis A. (2008) The predictability of extinction: biological and external correlates of decline in mammals. Proceedings of the Royal Society B, 275, 1441-1448.

Cardillo M., Mace G.M., Gittleman J.L., \& Purvis A. (2006) Latent extinction risk and the future battlegrounds of mammal conservation. Proceedings of the National Academy of Sciences of the United States of America, 103, 4157-4161.

Cardillo M., Mace G.M., Jones K.E., Bielby J., Bininda-Emonds O.R.P., Sechrest W., Orme C.D.L., \& Purvis A. (2005) Multiple causes of high extinction risk in large mammal species. Science, 309, 1239-1241.

Chen Y.-H. (2014) Areal sizes of high, intermediate, low and total suitable habitats are correlated to the global extinction risk for mammals. Archives of Biological Sciences, 66 , 963-967.

Davidson A.D., Hamilton M.J., Boyer A.G., Brown J.H., \& Ceballos G. (2009) Multiple ecological pathways to extinction in mammals. Proceedings of the National Academy of Science of the United States of America, 106, 10702-10705.

Ellis E.C., Klein Goldewijk K., Siebert S., Lightman D., \& Ramankutty N. (2010) Anthropogenic transformation of the biomes, 1700 to 2000. Global Ecology and Biogeography, 19, 589-606.

ESRI (1999) Arc View 3.2. Environmental Systems Research Institute, Redlandes, California, USA.

Fritz S.A., Bininda-Emonds O.R.P., \& Purvis A. (2009) Geographical variation in predictors of mammalian extinction risk : big is bad, but only in the tropics. Ecology Letters, 12, 538549.

González-Suárez M. \& Revilla E. (2013) Variability in life-history and ecological traits is a buffer against extinction in mammals. Ecology letters, 16, 242-51.

Goolsby E.W., Bruggeman J., \& Ane C. (2015) Rphylopars. Phylogenetic comparative tools for missing data within-species variation. $\mathrm{R}$ package version 0.1.1.

IUCN (2014) The IUCN Red List of Threatened Species. Version 2014.3. International Union for Conservation of Nature, http://www.iucnredlist.org/.

Jetz W. \& Freckleton R.P. (2015) Towards a general framework for predicting threat status of data-deficient species from phylogenetic, spatial and environmental information. Philosophical Transactions of the Royal Society B, 370, 20140016. 
Jones K.E., Bielby J., Cardillo M., Fritz S.A., O’Dell J., Orme C.D.L., Safi K., Sechrest W., Boakes E.H., Carbone C., Connolly C., Cutis M.J., Foster J.K., Grenyer R., Habib M., Plaster C.A., Price S.A., Rigby E.A., Rist J., Teacher A., Bininda-Emonds O.R.P., Gittleman J.L., Mace G.M., \& Purvis A. (2009) PanTHERIA : a species-level database of life history, ecology, and geography of extant and recently extinct mammals. Ecology, 90, 2648.

Liow L.H., Fortelius M., Lintulaakso K., Mannila H., \& Stenseth N.C. (2009) Lower extinction risk in sleep-or-hide mammals. The American naturalist, 173, 264-272.

Marco M. Di, Buchanan G.M., Szantoi Z., Holmgren M., Grottolo G., Gross D., Tranquilli S., Boitani L., \& Rondinini C. (2014) Drivers of extinction risk in African mammals : the interplay of distribution state, human pressure, conservation response and species biology. Philosophical Transactions of the Royal Society B, 369, 20130198.

Morrow E.H. \& Fricke C. (2004) Sexual selection and the risk of extinction in mammals. Proceeding of the Royal Scoiety of London, Series B, 271, 2395-2401.

Polishchuk L. V., Popadin K.Y., Baranova M.A., \& Kondrashov A.S. (2015) A genetic component of extinction risk in mammals. Oikos, 124, 983-993.

R Core Team (2014) $R$ : A language and environment for statistical computing. R Foundation for Statistical Computing, Vienna, Austria.

Verde Arregoitia L.D. (2016) Biases, gaps, and opportunities in mammalian extinction risk research. Mammal Review, 46, 17-29.

Verde Arregoitia L.D., Blomberg S.P., \& Fisher D.O. (2013) Phylogenetic correlates of extinction risk in mammals: species in older lineages are not at greater risk. Proceedings of the Royal Society B, 280, 20131092. 